\title{
əThe Dynamics of the Southwest Monsoon Current in 2016 from High-Resolution In Situ Observations and Models
}

\author{
Benjamin G. M. Webber, ${ }^{\mathrm{a}, \mathrm{b}}$ Adrian J. MAtThews, ${ }^{\mathrm{a}, \mathrm{c}}$ P. N. VinAyachandran, ${ }^{\mathrm{d}}$ C. P. NeEma, ${ }^{\mathrm{d}}$ \\ AlEJANDRA SANCHEZ-FrANKs, ${ }^{\mathrm{e}}$ V. ViJith,${ }^{\mathrm{f}}$ P. AMOL, ${ }^{\mathrm{g}}$ AND DARIUSZ B. BARANOWSKi ${ }^{\mathrm{h}}$ \\ ${ }^{a}$ Centre for Ocean and Atmospheric Sciences, School of Environmental Sciences, University of East Anglia, \\ Norwich, United Kingdom \\ ${ }^{\mathrm{b}}$ Climatic Research Unit, University of East Anglia, Norwich, United Kingdom \\ ${ }^{\mathrm{c}}$ School of Mathematics, University of East Anglia, Norwich, United Kingdom \\ ${ }^{\mathrm{d}}$ Centre for Atmospheric and Oceanic Sciences, Indian Institute of Science, Bangalore, India \\ ${ }^{\mathrm{e}}$ National Oceanography Centre, Southampton, United Kingdom \\ ${ }^{\mathrm{f}}$ School of Marine Sciences, Cochin University of Science and Technology, Kochi, India \\ ${ }^{\mathrm{g}}$ National Institute of Oceanography, Visakhapatnam, India \\ ${ }^{\mathrm{h}}$ Institute of Geophysics, Faculty of Physics, University of Warsaw, Warsaw, Poland
}

(Manuscript received 12 October 2017, in final form 14 July 2018)

\begin{abstract}
The strong stratification of the Bay of Bengal $(\mathrm{BoB})$ causes rapid variations in sea surface temperature (SST) that influence the development of monsoon rainfall systems. This stratification is driven by the salinity difference between the fresh surface waters of the northern bay and the supply of warm, salty water by the Southwest Monsoon Current (SMC). Despite the influence of the SMC on monsoon dynamics, observations of this current during the monsoon are sparse. Using data from high-resolution in situ measurements along an east-west section at $8^{\circ} \mathrm{N}$ in the southern BoB, we calculate that the northward transport during July 2016 was between 16.7 and $24.5 \mathrm{~Sv}\left(1 \mathrm{~Sv} \equiv 10^{6} \mathrm{~m}^{3} \mathrm{~s}^{-1}\right)$, although up to $2 / 3$ of this transport is associated with persistent recirculating eddies, including the Sri Lanka Dome. Comparison with climatology suggests the SMC in early July was close to the average annual maximum strength. The NEMO $1 / 12^{\circ}$ ocean model with data assimilation is found to faithfully represent the variability of the SMC and associated water masses. We show how the variability in SMC strength and position is driven by the complex interplay between local forcing (wind stress curl over the Sri Lanka Dome) and remote forcing (Kelvin and Rossby wave propagation). Thus, various modes of climatic variability will influence SMC strength and location on time scales from weeks to years. Idealized one-dimensional ocean model experiments show that subsurface water masses advected by the SMC significantly alter the evolution of SST and salinity, potentially impacting Indian monsoon rainfall.
\end{abstract}

\section{Introduction}

The monsoon depressions that originate over the Bay of Bengal (BoB) provide the majority of the monsoon rain that falls over northern and eastern India (e.g., Gadgil 2003). The active-break cycle of the Indian monsoon is largely driven by variations in the boreal summer intraseasonal oscillation (BSISO; Wang and Xie 1997). The propagation of the BSISO and the evolution of the active-break cycle over the BoB are

¿ Denotes content that is immediately available upon publication as open access.

Corresponding author: Benjamin Webber, b.webber@uea.ac.uk strongly influenced by local air-sea interaction, dependent on ocean mixed layer dynamics and stratification (Girishkumar et al. 2013).

The Southwest Monsoon Current (SMC; sometimes referred to as the Summer Monsoon Current) is a seasonal current that, during June-September, comprises a broad eastward flow that advects warm salty Arabian Sea high-salinity water (ASHSW) from the Arabian Sea into the southwest BoB (Murty et al. 1992; Vinayachandran et al. 1999; Jensen 2001; Jensen et al. 2016; Jain et al. 2017). As the SMC flows north, it subducts under the fresher

This article is licensed under a Creative Commons Attribution 4.0 license (http://creativecommons. org/licenses/by/4.0/). 
surface waters of the northern $\mathrm{BoB}$; strong mixing has been shown to bring ASHSW to the surface, altering the stratification and air-sea interactions that influence the monsoon (Vinayachandran et al. 2013). Therefore, understanding the variability of this current is crucial for understanding the monsoon system.

The SMC is driven by a combination of local and remote forcing (McCreary et al. 1993, 1996; Shankar et al. 2002). Local wind stress curl generates upwelling and low sea surface height (SSH) in the Sri Lanka Dome (SLD) to the west of the SMC (Vinayachandran and Yamagata 1998). McCreary et al. (1993) used a 2.5-layer model to show that the upper-layer shoaling associated with the SLD was absent without local wind stress, while the Rossby wave signal in the eastern $\mathrm{BoB}$ (and the associated upper-layer thickening) was absent when the equatorial wind stress was removed. Shankar et al. (2002) showed that the wind-forced seasonal cycle of the $\mathrm{BoB}$ can largely be described using a simple linear framework involving equatorial Kelvin waves that feed into the leaky coastal waveguide and in turn generate westwardpropagating Rossby waves. A standing anticyclonic eddy often forms to the southeast of the SLD and is also known to influence the strength of the SMC (Vinayachandran and Yamagata 1998; Wijesekera et al. 2016).

Several previous estimates have been made of the strength of the SMC at various points along its pathway. Schott et al. (1994) estimated the transport of the zonal current south of Sri Lanka to be $10-15 \mathrm{~Sv}\left(1 \mathrm{~Sv} \equiv 10^{6} \mathrm{~m}^{3} \mathrm{~s}^{-1}\right)$. Vinayachandran et al. (1999) estimated the seasonal mean northward flow to be $10 \mathrm{~Sv}$ using a 12-yr climatology of XBT observations along $6^{\circ} \mathrm{N}$. Wijesekera et al. (2016) estimated 8 or $16 \mathrm{~Sv}$ from moored current measurements at $8^{\circ} \mathrm{N}, 85^{\circ} \mathrm{E}$ scaled by a current width of 100 or $200 \mathrm{~km}$, respectively. Their study further revealed that intraseasonal fluctuations in the SMC are driven by the position of the SLD and the anticyclonic eddy to its southeast. Combining observations from a range of platforms, Lee et al. (2016) reveal energetic mixing and stirring of water masses at the boundary between the SLD and the SMC. Though the works cited here have made significant breakthroughs in our understanding of the SMC, there have been no synoptic-scale studies of the location and strength of the SMC, the total northward volume or water mass transport, or the processes that determine these features.

In this study, we use four gliders stationed approximately $1^{\circ}$ apart at $8^{\circ} \mathrm{N}$ between $85.3^{\circ}$ and $89.1^{\circ} \mathrm{E}$ as part of the BoB Boundary Layer Experiment (BoBBLE) project (Vinayachandran et al. 2018). Each glider sampled temperature and salinity in the top $1000 \mathrm{~m}$ of the water column approximately every $3 \mathrm{~h}$. This provides an unprecedented degree of vertical resolution (around $0.5-1 \mathrm{~m}$ ), and the horizontal coverage captures the majority of the northward flow of the SMC, its associated volume transport, and the key features of horizontal variability in velocity and salinity associated with the current. We find that the SMC is a surface-intensified current (upper $300 \mathrm{~m}$ ) that transports between 17 and $25 \mathrm{~Sv}$ northward, although between $1 / 2$ and $2 / 3$ of this transport is associated with recirculating eddy features including the SLD and the persistent anticyclonic eddy to the east of the SMC. The strength and location of the SMC are determined by the complex interplay between the timing and strength of local and remote forcing. The observations and model runs used in this study are outlined in section 2 . In section 3 the strength and structure of the SMC is calculated from observations and numerical model simulations. The local and remote forcing of the 2016 SMC, and the seasonal to interannual variability of these processes, are investigated in section 4. The role of ocean dynamics in determining the location of the SMC is assessed in section 5. The impact of the subsurface salinity maximum on the stratification and surface temperature in the $\mathrm{BoB}$ is examined in section 6. The discussion of these results is presented in section 7 .

\section{Observations, models, and methodology}

The BoBBLE field campaign took place during the 2016 southwest monsoon season. The observations presented here include the measurements of temperature, salinity, density, pressure, and velocity from both the gliders and the ship between 1 and 20 July 2016 . During this period the monsoon conditions in the southern BoB were in a break phase with high solar insolation, very little precipitation, and southwesterly winds of approximately $10 \mathrm{~m} \mathrm{~s}^{-1}$ (Vinayachandran et al. 2018). A complete description of the observations gathered and the prevailing climatic conditions during the BoBBLE field campaign are detailed in Vinayachandran et al. (2018).

Figure 1 shows the ship track and the location of the gliders used in this study from 24 June to 23 July 2016. The westernmost glider (SG579) was deployed at $86^{\circ} \mathrm{E}$ on $30 \mathrm{June}$ and transited to $85.3^{\circ} \mathrm{E}$, arriving on $8 \mathrm{July}$. All other gliders were deployed in virtual mooring mode at fixed locations along $8^{\circ} \mathrm{N}$ while taking vertical profiles. Conductivity-temperature-depth (CTD) observations were made along the section at $8^{\circ} \mathrm{N}$ on both the outward $\left(\sim 1^{\circ}\right.$ longitude spacing $)$ and return $\left(\sim 0.2^{\circ}\right.$ longitude spacing) legs of the cruise. Northward geostrophic velocities calculated from the gradient in density between these CTD casts were referenced to northward velocity calculated by combining data from two shipboard acoustic Doppler current profilers (ADCPs) operating at 150 and $38 \mathrm{kHz}$. Following Thompson and Heywood (2008) and Damerell et al. (2013), the depth range 


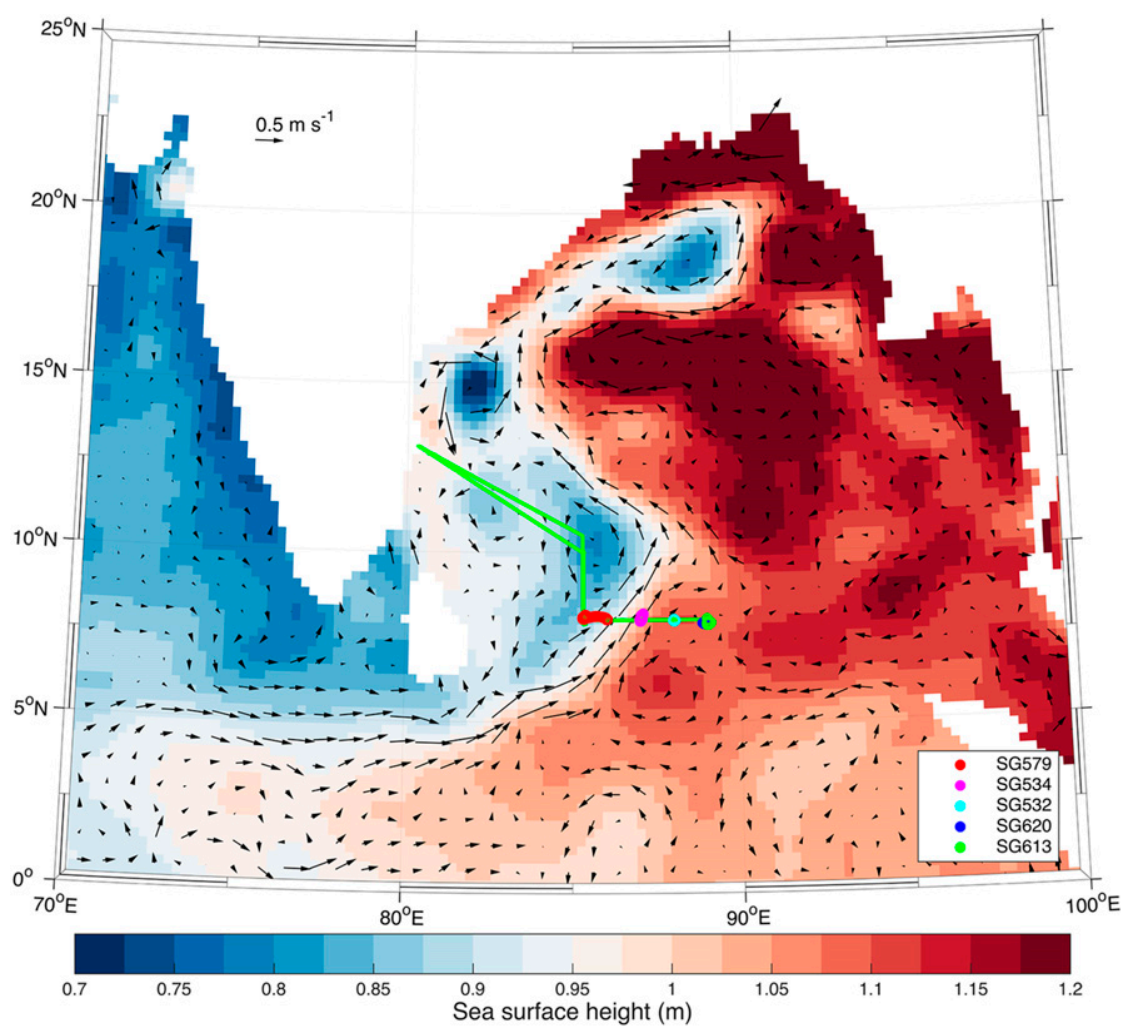

FIG. 1. (a) Sea surface height (shaded; $m$ ) and resultant surface geostrophic velocity (vector; $\mathrm{m} \mathrm{s}^{-1}$ ) from AVISO, averaged over 1-20 Jul 2016, to coincide with the BoBBLE cruise. The cruise track is shown in green, and the glider locations are plotted as color-coded circles.

where the geostrophic shear best matched the shear from the ADCP was selected. The barotropic adjustment was then calculated as the difference between the geostrophic and ADCP velocity within this depth range, which was estimated to be $100-500 \mathrm{~m}$.

The gliders spanned the majority of the SMC $\left(85.3^{\circ}-\right.$ $89^{\circ} \mathrm{E}$ ), thus enabling us to estimate the total northward geostrophic transport of the current. Density was calculated using measurements of temperature, salinity, and pressure from the gliders. Quality control was performed for each glider, based on analysis in Conservative Temperature-Absolute Salinity $\left(\Theta-S_{\mathrm{A}}\right)$ space for the entire dataset and in depth space for individual dives. Salinity data were rejected when the glider vertical velocity was less than $0.035 \mathrm{~m} \mathrm{~s}^{-1}$ to ensure good flow through the unpumped conductivity-temperature (CT) sensor. The CT sensors were factory calibrated, and in situ calibration was performed against the ship CTD observations at deployment and recovery. The difference between glider and ship observations was minimized in conductivity-temperature space to remove the effect of internal waves. No temperature offsets were applied as a result of in situ calibration, and the conductivity offsets applied were small.
Before calculating the geostrophic shear, the glider observations are projected onto a regular depth-time grid with 1-m and 1-day spacing in depth and time, respectively, using optimal interpolation (Bretherton et al. 1976). Following the methodology of Webber et al. (2014) and Matthews et al. (2014), we initially construct a background field at each grid point $\left(z_{j}, t_{j}\right)$ using a two-dimensional Gaussian-weighting function to determine the weight $w_{i j}$ of each observation at point $\left(z_{i}, t_{i}\right)$ as

$$
w_{i j}=\exp \left\{-\left[\left(\frac{z_{i}-z_{j}}{z_{r}}\right)^{2}+\left(\frac{t_{i}-t_{j}}{t_{r}}\right)^{2}\right]\right\},
$$

where the radii of influence $\left(z_{r}, t_{r}\right)$ are set to $2 \mathrm{~m}$ and 1 day in the vertical and time dimensions, respectively. The covariances of the data are estimated using the same Gaussian function [Eq. (1)] and used to define the analysis increment that is then added to the background field to calculate the final optimally interpolated data. The temporal radius of influence was chosen to minimize the impact of diurnal waves in the data, which were dominated by a semidiurnal (M2) signal. The Gaussianweighted average with $t_{r}=1$ day of an idealized M2 
wave removes more than $99.9 \%$ of the original tidal signal. The ability to filter out internal waves in this manner represents a significant advantage for calculating geostrophic velocities using multiple continuous observations compared to using a traditional CTD section. A potential concern is that near-inertial oscillations will obscure the signal of interest. However, a spectral analysis actually shows weak power in the 3-4-day period range associated with these features. As filtering to remove near-inertial oscillations would introduce edge effects on the relatively short time series used here, we have not removed these oscillations.

The geostrophic shear between any pair of gliders is calculated from the gradient in dynamic height anomaly (i.e., the integral of the specific volume with respect to a standard pressure level; here $p=0$ ) between the optimally interpolated data for each glider, using the Thermodynamic Equation of Seawater 2010 (TEOS-10) framework (McDougall et al. 2010) and the Gibbs seawater toolbox (McDougall and Barker 2011). Each daily estimate of geostrophic velocity was derived from optimally interpolated temperature and salinity data, which takes a weighted estimate of all available profiles, but with the exponential decay scale of 1 day corresponding to approximately 12 profiles (six dives, each dive taking around $4 \mathrm{~h}$ ) for each glider. The barotropic offset is calculated by subtracting the vertical mean of the geostrophic velocity between the surface and the maximum depth of the dive from the dive-averaged current (DAC), taking into account variations in dive depths. The average of these barotropic offsets for each day and glider pair is then added to the relevant geostrophic velocity profile to obtain the absolute geostrophic velocities presented here. The DAC values are calculated as the discrepancy between the horizontal displacement during the dive estimated from the glider hydrodynamic model and the distance between the pre- and postdive GPS locations. To achieve the highest possible accuracy, an in situ compass calibration was carried out during the mission for all gliders and the hydrodynamic model was optimized by minimizing the net upwelling over the entire deployment, following the method of Frajka-Williams et al. (2011).

To provide context for the in situ observations and to study the development and propagation of dynamic features, as well as the interannual variability of key processes, several satellite products are used: SSH and geostrophic velocities from AVISO; wind data from the Advanced Scatterometer (ASCAT) instrument; and the weekly dipole mode index data, calculated by the $\mathrm{Na}$ tional Oceanic and Atmospheric Administration (NOAA) from the Reynolds OISSTv2 analysis.

Three ocean models are used in this study: The first is the Nucleus for European Modelling of the Ocean
(NEMO) $1 / 12^{\circ}$ global model with data assimilation, freely available from 2007 to present through the Copernicus Marine Environment Monitoring Service (CMEMS; http://marine.copernicus.eu; product ID: GLOBAL_ANALYSIS_FORECAST_PHY 001 024). This product uses NEMO, version 3.1 (Madec et al. 2008), with 50 vertical levels ranging in thickness from $1 \mathrm{~m}$ at the surface to $450 \mathrm{~m}$ at the bottom and comprising 22 levels in the upper $100 \mathrm{~m}$. It is forced at the surface by data from the European Centre for Medium-Range Weather Forecasts (ECMWF) Integrated Forecast System at 3-h resolution to reproduce the diurnal cycle. The model assimilates satellite SST, SSH, and in situ temperature and salinity as well as sea ice concentration and thickness. The in situ data are collected from the main global networks (including Argo floats, glider observations, moorings, and research vessels), and these data are available through CMEMS (product ID: INSITU_GLO_NRT_OBSERVATIONS_013_030). Note that the BoBBLE data were not assimilated into this model.

The second model is a $1 / 4^{\circ}$ regional configuration of the Modular Ocean Model (MOM) based on GFDL MOM4p1 and run specifically for this project from May to September 2016. The model has 58 vertical levels with 1-m vertical resolution near the surface. The physical parameterizations are as specified in Behara and Vinayachandran (2016), and the model configuration and spinup are described in Das et al. (2016). The model is forced at the surface with daily data from ERA-Interim (Dee et al. 2011), with sponge layers at the open lateral boundaries [see Das et al. (2016) for details]. This model configuration has previously been successful in simulating many key features of the circulation in the BoB (Behara and Vinayachandran 2016; Das et al. 2016). Here, the model is run with a limitedarea domain over the Indian Ocean within $30^{\circ} \mathrm{S}-30^{\circ} \mathrm{N}$, $30^{\circ}-120^{\circ} \mathrm{E}$.

The third model used is the one-dimensional $K$-profile parameterization (KPP) model of vertical mixing (Large et al. 1994), described in section 6. We use this idealized framework to investigate how the subsurface ASHSW advected by the SMC will influence the evolution of SST in the BoB. An idealized one-dimensional model is the optimal tool to use for such investigation, since it enables the influence of subsurface structure on SST to be investigated in the absence of horizontal advection and atmospheric feedbacks.

\section{The Southwest Monsoon Current in 2016}

\section{a. Surface velocity}

The path of the SMC in 2016 is apparent from the AVISO data (Fig. 1), originating in the eastward flow along $5^{\circ} \mathrm{N}$ between $70^{\circ}$ and $82^{\circ} \mathrm{E}$. This SMC turns 

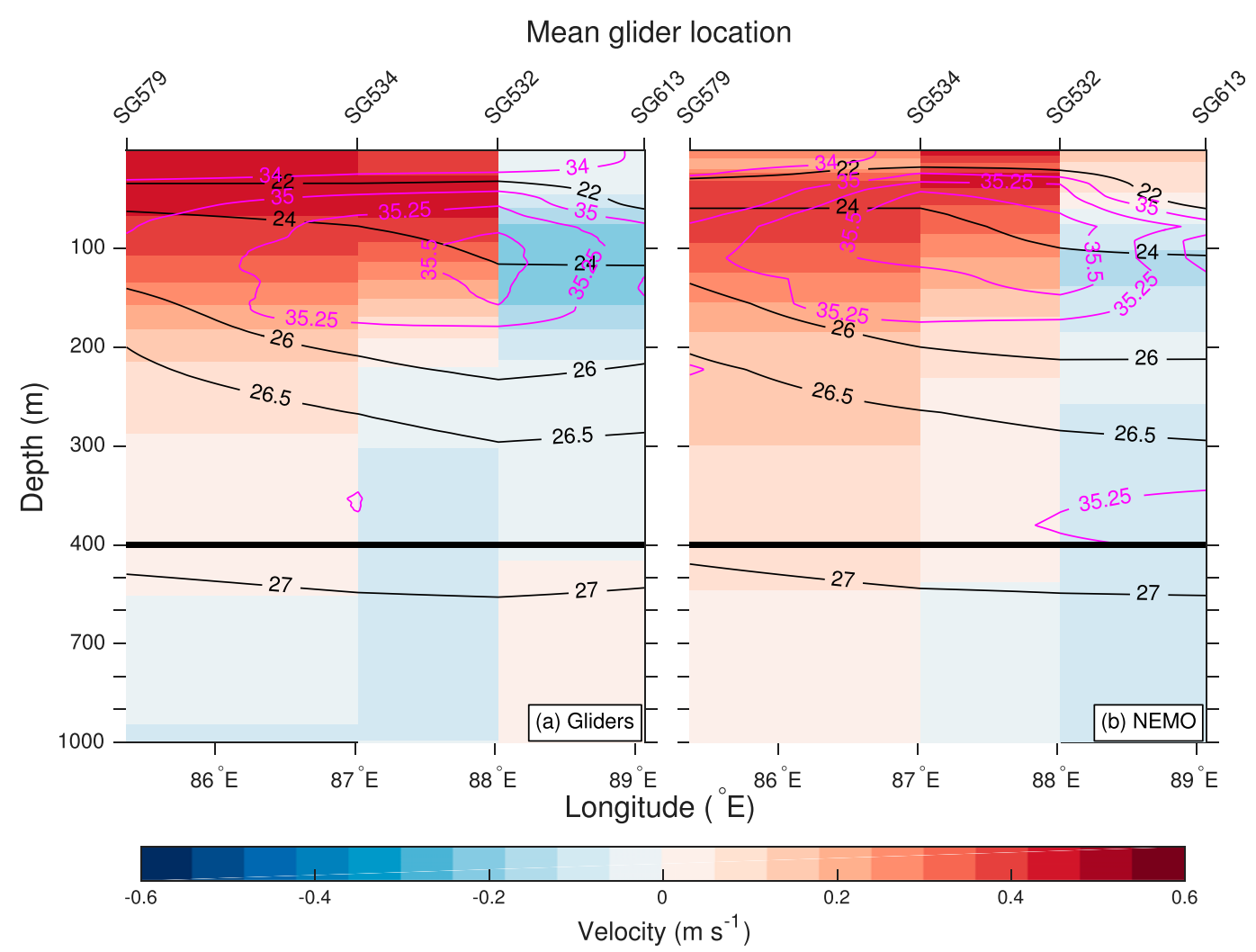

FIG. 2. (a) Time-mean (5-15 Jul 2016) northward geostrophic velocity (shaded; $\mathrm{m} \mathrm{s}^{-1}$ ), optimally interpolated potential density $-1000 \mathrm{~kg} \mathrm{~m}^{-3}$ (black contours at 22, 24, 26, 26.5, and $27 \mathrm{~kg} \mathrm{~m}^{-3}$ ) and Absolute Salinity (magenta contours at $34,35,35.25$, and $35.5 \mathrm{~g} \mathrm{~kg}^{-1}$ ) against time-mean glider longitude. (b) As in (a), but for northward velocity, density, and Absolute Salinity at $8^{\circ} \mathrm{N}$ from the NEMO model averaged between daily glider locations. Note the change in vertical scale at $400 \mathrm{~m}$.

northeastward to the southeast of Sri Lanka, as it flows along the SSH gradient between the anticyclonic vortex centered on $6^{\circ} \mathrm{N}, 87.5^{\circ} \mathrm{E}$ and the SLD, centered on $10^{\circ} \mathrm{N}$, $85^{\circ} \mathrm{E}$. High SSH to the east represents the propagation of Rossby waves leaked from the coastal waveguide at the eastern boundary of the BoB (Shankar et al. 2002). North of $8^{\circ} \mathrm{N}$ the SMC splits into multiple flows, with eddies forming along the flanks of the current. During July 2016, the most coherent pathway is along the $1-\mathrm{m}$ SSH contour, which meanders northward to $20^{\circ} \mathrm{N}$, where it joins the southward-flowing East India Coastal Current (EICC). As the EICC flows along the east coast of India and Sri Lanka, some of this water gets entrained into the western side of the SMC where the flows converge at around $6^{\circ} \mathrm{N}, 82^{\circ} \mathrm{E}$.

\section{b. Time-mean structure}

Here we examine the vertical and zonal structure of the SMC for July 2016 using time-mean northward velocity and transport from the glider observations (Fig. 2a). Strong northward flow between $85.3^{\circ}$ and $88^{\circ} \mathrm{E}$ reaches a maximum depth of approximately $550 \mathrm{~m}$ between $85.3^{\circ}$ and $87^{\circ} \mathrm{E}$ (i.e., between gliders SG579 and SG534). The northward flow between $87^{\circ}$ and $88^{\circ} \mathrm{E}$ exhibits a subsurface maximum at around 50-m depth and is weakly negative (southward) below about $200 \mathrm{~m}$. Meanwhile the flow between $88^{\circ}$ and $89^{\circ} \mathrm{E}$ is southward above $500 \mathrm{~m}$, with a subsurface maximum southward flow between 80 and $150 \mathrm{~m}$. This suggests a baroclinic recirculation or eddy feature approximately centered on $88^{\circ} \mathrm{E}$, consistent with the inflection of the isopycnals at this longitude.

The vertical salinity structure is characterized by a fresh surface mixed layer, generally less than $34 \mathrm{~g} \mathrm{~kg}^{-1}$, beneath which salinity increases sharply, with the $35 \mathrm{~g} \mathrm{~kg}^{-1}$ contour between 50 and $80 \mathrm{~m}$ (Fig. 2a). Throughout the BoB there is a broad subsurface salinity maximum between around 150 - and $800-\mathrm{m}$ depth, typically peaking at $200-300 \mathrm{~m}$ with salinity around $35.1 \mathrm{~g} \mathrm{~kg}^{-1}$ (Jain et al. 2017) and associated with the dominant water mass for this region, North Indian Central Water (NICW; You and Tomczak 1993). Though this salinity maximum is evident in the glider data, it is overwhelmed by the strength of the smaller-scale yet stronger salinity 
maximum between 50 and $200 \mathrm{~m}$, centered on $88^{\circ} \mathrm{E}$ and peaking at over $35.5 \mathrm{~g} \mathrm{~kg}^{-1}$. This shallower salinity maximum is associated with the transport of ASHSW into the BoB by the SMC (Vinayachandran et al. 1999; Jensen 2001; Jensen et al. 2016; Vinayachandran et al. 2013; Jain et al. 2017). The absence of this salinity maximum from the western side of the current in both the observations and the model suggests that the water along this side of the current originates from the northern $\mathrm{BoB}$ or is influenced by the upwelling in the SLD.

For comparison with the glider data, we calculate the time-mean northward velocity from the NEMO model by first averaging the daily model data between the daily mean longitudes of each pair of gliders and then taking the time mean (Fig. 2b). The agreement is strong, showing similar structure and magnitude of the northward flow, including the recirculation and southward flow to the east. Further, the salinity maximum associated with ASHSW has approximately the same strength and location, although the model suggests this feature is slightly stronger and extends slightly farther to the west. The near-surface flow in the model also deviates slightly from the observations, with weaker northward flow between $85.3^{\circ}$ and $87^{\circ} \mathrm{E}$ than in the observations and northward flow between $88^{\circ}-89^{\circ} \mathrm{E}, 0-50 \mathrm{~m}$, where the observations suggest southward flow. These near-surface discrepancies may be partly due to ageostrophic Ekman flow not accounted for by the gliders.

Figure 3 shows the full-resolution longitude-depth plots from the NEMO $1 / 12^{\circ}$ data-assimilating ocean model and the MOM $14^{\circ}$ ocean model at $8^{\circ} \mathrm{N}$ between $82^{\circ}$ and $90^{\circ} \mathrm{E}$. The time-mean velocity during the BoBBLE deployment (5-15 July 2016) from NEMO shows a strong and deep jet around $87^{\circ} \mathrm{E}$, with a clear subsurface maximum in northward velocity at around 50-100 m (Fig. 3a). The eastward velocity signal associated with the SMC is shallow, with the strongest velocity at the surface and weak flow beneath $100 \mathrm{~m}$. This zonal flow is stronger in climatology than the meridional flow, while in 2016 the subsurface maximum of the meridional flow is stronger. The extensive eastward flow along $8^{\circ} \mathrm{N}$ in the climatology is consistent with the typical pathway of the SMC that forms an eastward-flowing branch along approximately $8^{\circ} \mathrm{N}$ (e.g., Vinayachandran et al. 1999, 2013), yet this zonal flow was relatively weak in 2016 (Fig. 1).

It is clear that the BoBBLE section captures the majority of the northeastward flow during the observed period. In contrast, the 2007-13 climatology for the same period suggests that the SMC is usually farther west at this point in the year but highlights how much weaker both the SMC and the subsurface salinity maximum are in climatologies, partly due to the smearing out of these spatially and temporally varying features. In addition, the observations in 2016 represent a short snapshot and may include contributions from eddies that are not always present in other years.

The nonassimilating MOM model does not capture the location of the SMC in 2016 accurately (Figs. 3e,f), although the near-surface eastward flow agrees with both 2016 (Fig. 3b) and climatology (Fig. 3d) in the NEMO model. In the MOM model, the location of the northward flow is much closer to climatology than the observed flow in 2016, although the maximum northward velocity is approximately correct. Further, the salinity shows little evidence of the subsurface salinity maximum at $100-\mathrm{m}$ depth, which was evident in the NEMO model and glider observations (Fig. 2), although this feature is more evident further south (not shown). These differences highlight the difficulty in accurately simulating the strength and location of this current and its subsequent impact on subsurface water masses in even fairly high-resolution $\left(1 / 4^{\circ}\right)$ ocean models without data assimilation.

\section{c. SMC volume transport}

From the glider observations we calculate the timemean total northward geostrophic transport (i.e., ignoring the southward flow) between $85.3^{\circ}$ and $88^{\circ} \mathrm{E}$ to be $21.0 \mathrm{~Sv}$ between 5 and $15 \mathrm{July}$, giving daily average values between 16.7 and $24.5 \mathrm{~Sv}$ during this period. There are two sources of uncertainty in this estimate: sampling uncertainty due to the limited spatial coverage of the observations and measurement uncertainty due to errors in the temperature, salinity, and dive-averaged current observations. We estimate the sampling uncertainty by subsampling the NEMO model velocity at the glider locations and comparing the resultant transport with that calculated from the model velocity at standard resolution. This comparison suggests that the glider sampling underestimates the total transport by up to $5 \mathrm{~Sv}$. However, this is partly compensated by the overestimation of total transport by the geostrophic approximation, since the cyclonic curvature of the SMC around the SLD means that the true velocity is less than the geostrophic velocity. As a result, the mean bias of the geostrophic, subsampled transport relative to the total transport is $-0.6 \mathrm{~Sv}$, with a root-mean-square error of $2.8 \mathrm{~Sv}$.

We estimate the measurement uncertainty associated with temperature $\left[O(0.001)^{\circ} \mathrm{C}\right]$ and salinity $[O(0.01)$ $\left.\mathrm{g} \mathrm{kg}^{-1}\right]$ observations by applying random fluctuations of these magnitudes to the observations; the resultant uncertainty in transport is negligible $[O(0.01) \mathrm{Sv}]$. However, the uncertainty in DAC estimates of $O(0.01) \mathrm{m} \mathrm{s}^{-1}$ 

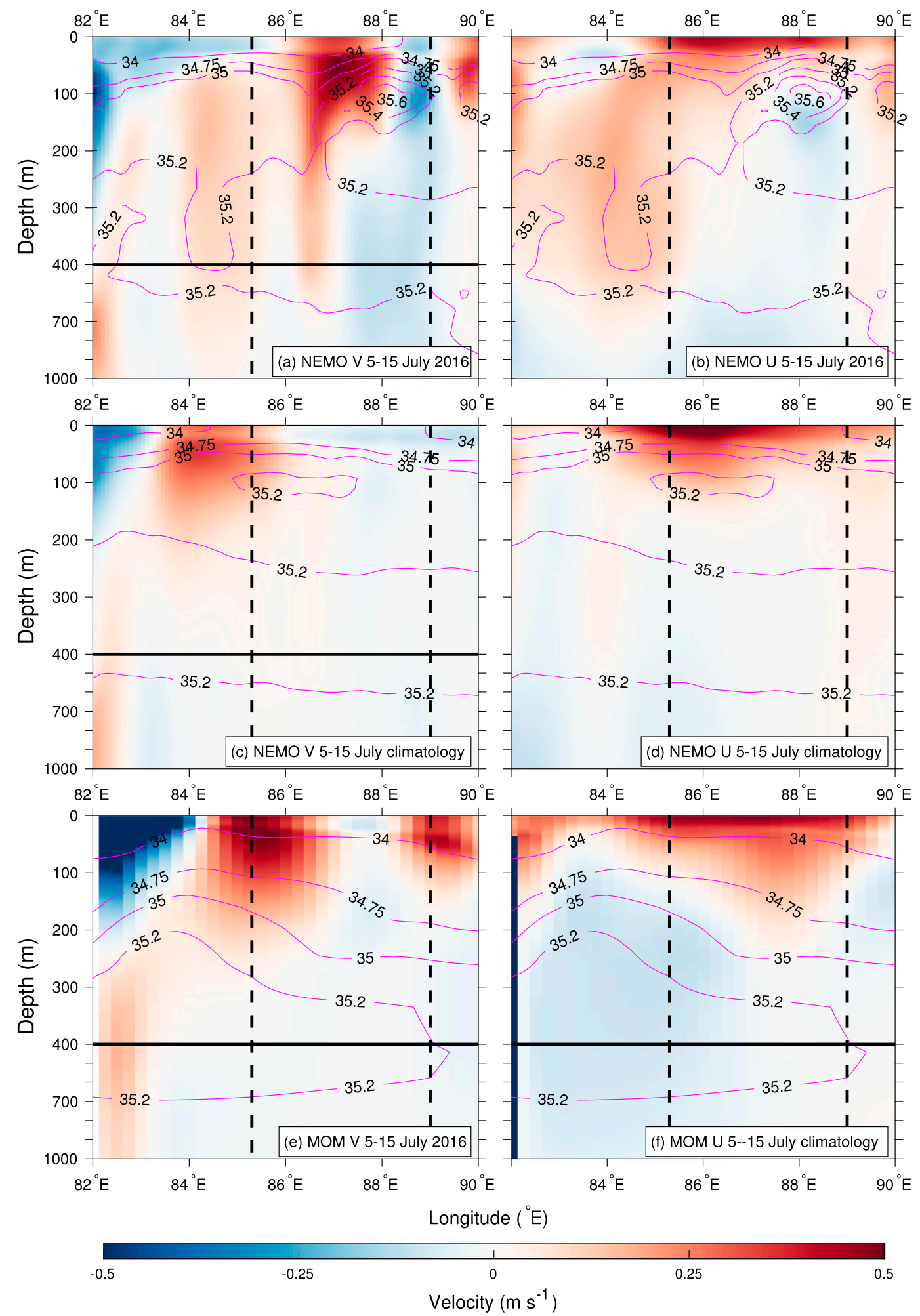

FIG. 3. (left) Northward and (right) eastward velocity (shaded; $\mathrm{m} \mathrm{s}^{-1}$ ) and Absolute Salinity (contoured at 34, $34.75,35,35.2,35.4$, and $35.6 \mathrm{~g} \mathrm{~kg}^{-1}$ ) at $8^{\circ} \mathrm{N}$ for (a),(b) NEMO averaged over 5-15 Jul 2016, (c),(d) NEMO 5-15 Jul 2007-16 climatology and (e),(f) MOM averaged over 5-15 Jul 2016. The longitudinal limits of the BoBBLE campaign are highlighted by black vertical dashed lines. Note the change in vertical scale at $400 \mathrm{~m}$. 

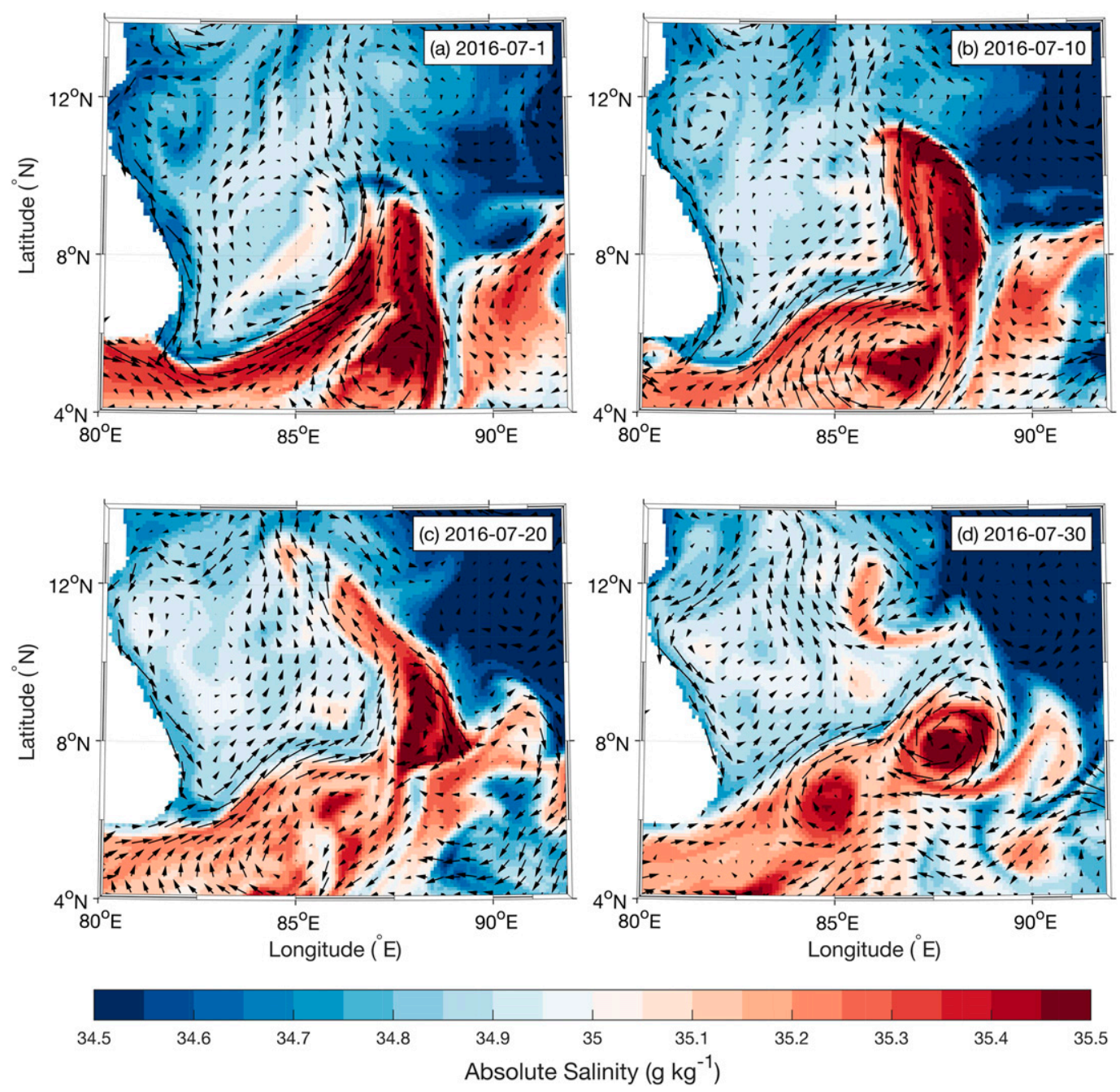

FIG. 4. Daily mean velocity (vectors; $\mathrm{m} \mathrm{s}^{-1}$ ) and Absolute Salinity (shaded; $\mathrm{g} \mathrm{kg}^{-1}$ ) at $110 \mathrm{~m}$ from the NEMO model for (a) 1, (b) 10, (c) 20, and (d) $30 \mathrm{Jul} 2016$.

(Todd et al. 2011) is not negligible and contributes an uncertainty of $O(1) \mathrm{Sv}$ to the transport estimates. Combined with the sampling uncertainty, we estimate the total uncertainty to be approximately $\pm 4 \mathrm{~Sv}$.

The current width is around $300 \mathrm{~km}$ at the surface, consistent with the $3^{\circ}$ width stated by Schott et al. (1994) for the eastward current south of Sri Lanka and the $300 \mathrm{~km}$ found by Vinayachandran et al. (1999) at $6^{\circ} \mathrm{N}$ in the BoB but larger than the $100-200 \mathrm{~km}$ used by Wijesekera et al. (2016) in estimating their maximum transport of 8-16 Sv. It is clear that some of the northward transport is associated with recirculating eddies, including the SLD to the west and the persistent anticyclonic eddy centered on $88^{\circ} \mathrm{E}$ (Fig. 1). We investigate the temporal variability of these features by examining daily mean velocity and salinity at $110 \mathrm{~m}$ from the NEMO model (Fig. 4). The SLD is at the center of a large cyclonic circulation extending over $82^{\circ}-86^{\circ} \mathrm{E}$, $5^{\circ}-15^{\circ} \mathrm{N}$, encompassing the SMC and the EICC. Meanwhile, the anticyclonic recirculation to the east is centered on $88^{\circ} \mathrm{E}$ and extends from $4^{\circ}$ to $10^{\circ} \mathrm{N}$ on 1 July (Fig. 4a). This feature subsequently splits into two quasi-stationary eddies and is clearly linked to the presence of the subsurface salinity maximum since the core of these eddies are associated with salinity maxima (Fig. 4d).

If we defined the SMC as only the portion of the current that is continuous from the Arabian Sea into the $\mathrm{BoB}$, then the transport would be substantially less than the total northward transport estimated from the observations since the latter includes the contribution of recirculations. However, such a separation is difficult in practice since there is no clear boundary between the continuous and recirculating portions of the flow, and 
the seasonally varying SMC is not well separated in spatial or temporal scale from the SLD, Rossby waves, and persistent eddy features evident in Fig. 4. If we assume that the subsurface salinity maximum indicates the portion of the current that originated in the Arabian Sea, then the width of this part of the current is around $150 \mathrm{~km}$, although some of this subsequently recirculates in the anticyclonic eddy to the east of the SMC. Therefore, the total SMC transport from the Arabian Sea into the $\mathrm{BoB}$ may be between $1 / 3$ and $1 / 2$ of the observed northward transport, or 7-10.5 Sv.

To evaluate the influence of high-frequency variability on our transport estimate, we calculate the zonal mean velocity between $84^{\circ}$ and $88^{\circ} \mathrm{E}$ at the surface from AVISO altimetry data and at various levels from the NEMO data (Fig. 5). This analysis shows that the observational period was during strong northward surface flow and anomalously positive velocity at $500 \mathrm{~m}$. The dominant variability at all levels has periodicity longer than 20 days, with little evidence of high-frequency eddy variability in the velocity or transport data.

\section{d. Temporal variability}

The glider observations of DACs (Fig. 6a) show the strength and direction of the currents averaged between the surface and either 700 or $1000 \mathrm{~m}$, depending on the dive. The DACs are strong and predominantly northward between $85^{\circ}$ and $87^{\circ} \mathrm{E}$, but with considerable variability in strength and direction between dives. The DACs turn progressively clockwise farther east and are predominantly southward at $89^{\circ} \mathrm{E}$, consistent with surface (Fig. 1) and geostrophic (Fig. 2) currents. The surface drift (calculated from GPS measurements at the surface) is much stronger than the DAC and is predominantly northeastward between $85^{\circ}$ and $87^{\circ} \mathrm{E}$, becoming eastward at $88^{\circ} \mathrm{E}$ and highly variable at $89^{\circ} \mathrm{E}$. There is consistency in the direction and strength of the surface drift and depth-averaged current between the two gliders close to $89^{\circ} \mathrm{E}$ (SG620 and SG613; Fig. 1), giving us confidence in the reliability of these observations. Furthermore, the difference in velocity between these surface drift observations and the surface geostrophic currents derived from altimetry is close to what would be expected owing to the combination of surface Ekman drift and Stokes drift (not shown).

The temporal variability of the northward geostrophic currents during this campaign is shown from the glider data (Fig. 7) and CTD transects referenced to the shipboard ADCP (Fig. 8). These figures consistently show a weakening and westward shift of the SMC during the observational period (see also Fig. 9). There is strong agreement between the ship and glider estimates of the geostrophic current, although the higher horizontal resolution of the

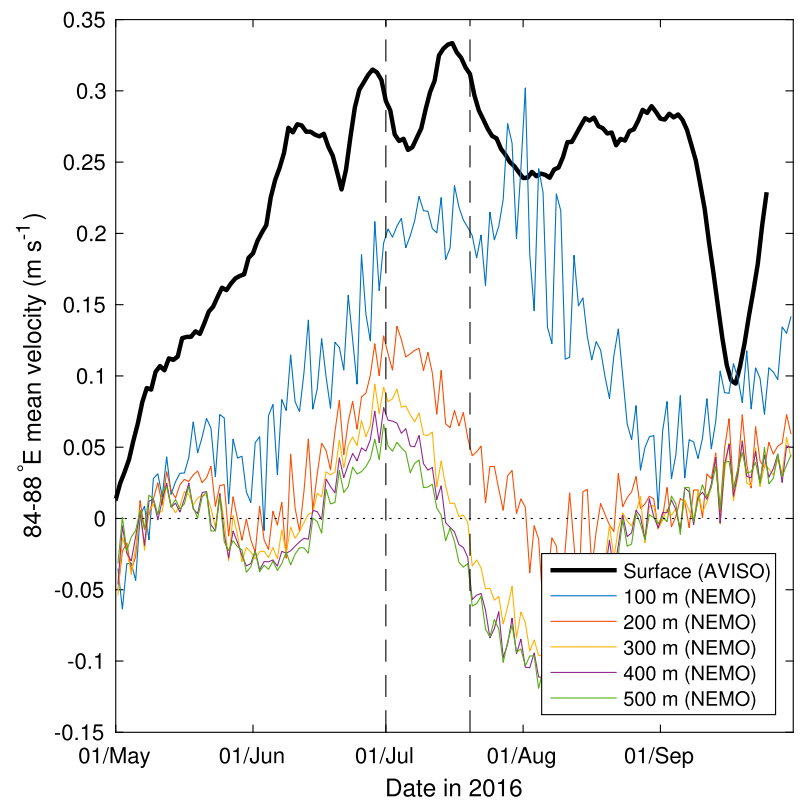

FIG. 5. Mean northward velocity between $84^{\circ}$ and $88^{\circ} \mathrm{E}\left(\mathrm{m} \mathrm{s}^{-1}\right)$ from surface AVISO altimetry data (thick black line) and NEMO model data at 100-500 m (thin lines; see legend). The observed period (1-20 Jul) is shown by vertical dashed lines; the dotted line indicates zero northward velocity.

CTD and ADCP observations suggest the peak northward flow of the SMC was stronger (maximum $0.8 \mathrm{~m} \mathrm{~s}^{-1}$ ) than resolved by the gliders (maximum $0.6 \mathrm{~m} \mathrm{~s}^{-1}$ ). All three glider pairings show subsurface maxima in current speed at times, most consistently present in the southward flow between SG532 and SG613.

The glider and satellite estimates of the surface geostrophic current agree well (Figs. 9a,e), although the gliders suggest a slightly weaker peak flow, possibly as a result of the zonal averaging of the glider data. The altimetry suggests mean northward surface flow between $88^{\circ}$ and $89^{\circ} \mathrm{E}$ before $8 \mathrm{July}$, which contrasts with the near-zero glider-derived surface velocity at this time. Some of the discrepancies between the glider and altimetry data may be due to the spatial and temporal smoothing involved in the optimal interpolation of the AVISO altimetry data, for which the decorrelation length scales (equivalent to direction-dependent radii of influence; see section 2) at $8^{\circ} \mathrm{N}$ are 250 and $313 \mathrm{~km}$ in the zonal and meridional directions, respectively (Le Traon et al. 1998).

At $100 \mathrm{~m}$, the glider observations suggest that the core of the SMC initially shifted eastward before returning back to the west (Fig. 9b). The subsurface salinity maximum observed between $87^{\circ}$ and $88^{\circ} \mathrm{E}$ (SG534-SG532; Fig. 7b) weakens suddenly and dramatically around 8-9 July, coinciding with the strongest northward flow between this glider pair and therefore the time when the 


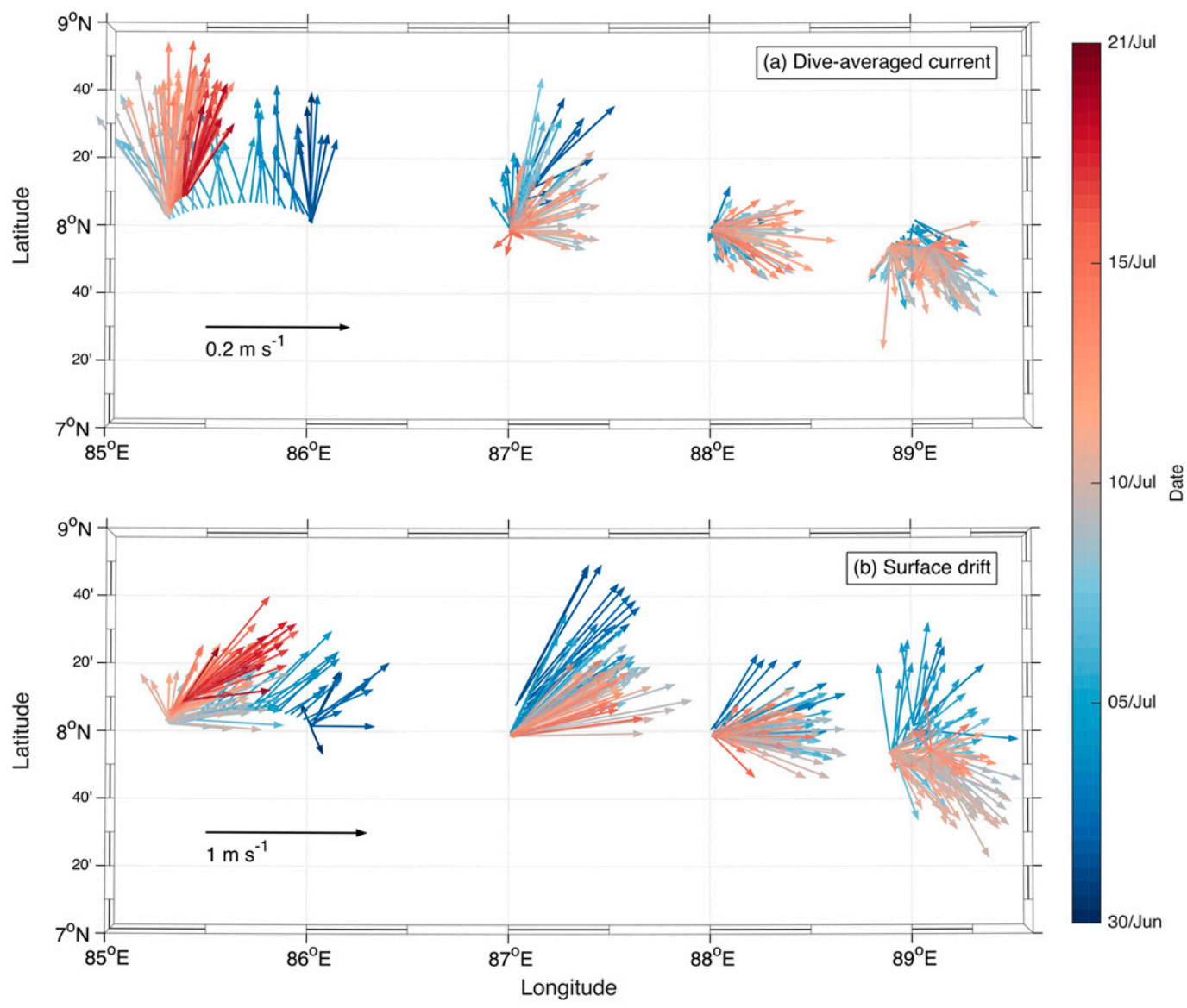

FIG. 6. Glider-derived velocities (vectors; $\mathrm{m} \mathrm{s}^{-1}$ ), colored by date: (a) dive-averaged current and (b) surface drift.

SMC core was farthest to the east. Further investigation shows that this sudden drop in salinity was only present at $87^{\circ} \mathrm{E}$, on the flanks of the subsurface salinity core, while the salinity at $88^{\circ} \mathrm{E}$ was stable (not shown), suggesting that this variability is most likely due to the longitudinal shift in the SMC and the associated shift in the advection of ASHSW. The rapidity of the change in salinity also suggests that there is a sharp front between this water mass and the relatively fresh water farther to the west. Similar high-frequency variability at the depth of the subsurface salinity maximum is seen at $89^{\circ} \mathrm{E}$ (Fig. 7c), possibly indicative of filaments or eddies sheared off from the main path of the SMC, similar to those found by Lee et al. (2016) farther west.

As in the time mean, there is strong agreement between the glider northward geostrophic velocity and the NEMO northward velocity (Figs. 9b-d,f-h) at 100 and $250 \mathrm{~m}$; however, the agreement weakens at $600 \mathrm{~m}$ (and at other depths below around $400 \mathrm{~m}$; not shown). At $100 \mathrm{~m}$ (Figs. 9b,f) the modeled northward velocity associated with the SMC is too strong at the start of the time series. At this depth there is evidence of an eastward shift in the core of the SMC in the model and observations between 1 and 10 July, after which the observations imply a westward shift that is much less pronounced in the NEMO model. At $250 \mathrm{~m}$ (Figs. 9c,g), the modeled temporal variability agrees very well with the observed weakening of the northward flow at the western end of the section. Overall we conclude that the NEMO model faithfully represents the variability of the SMC.

\section{Dynamics controlling the SMC}

This section investigates the variability in the strength and location of the SMC throughout the summer of 2016 and examines how this year compares with climatology. Given that the strength and location of the SMC is determined by the SSH gradient between the SLD to the west and higher SSH propagating as a dynamic signal from the eastern boundary of the BoB (e.g., Shankar et al. 2002), we examine the strength and timing of the $\mathrm{SSH}$ gradient features and their interaction from 2012 to 2016.

The propagation pathway of the dynamic wave signal from the equator around the coast and the subsequent 

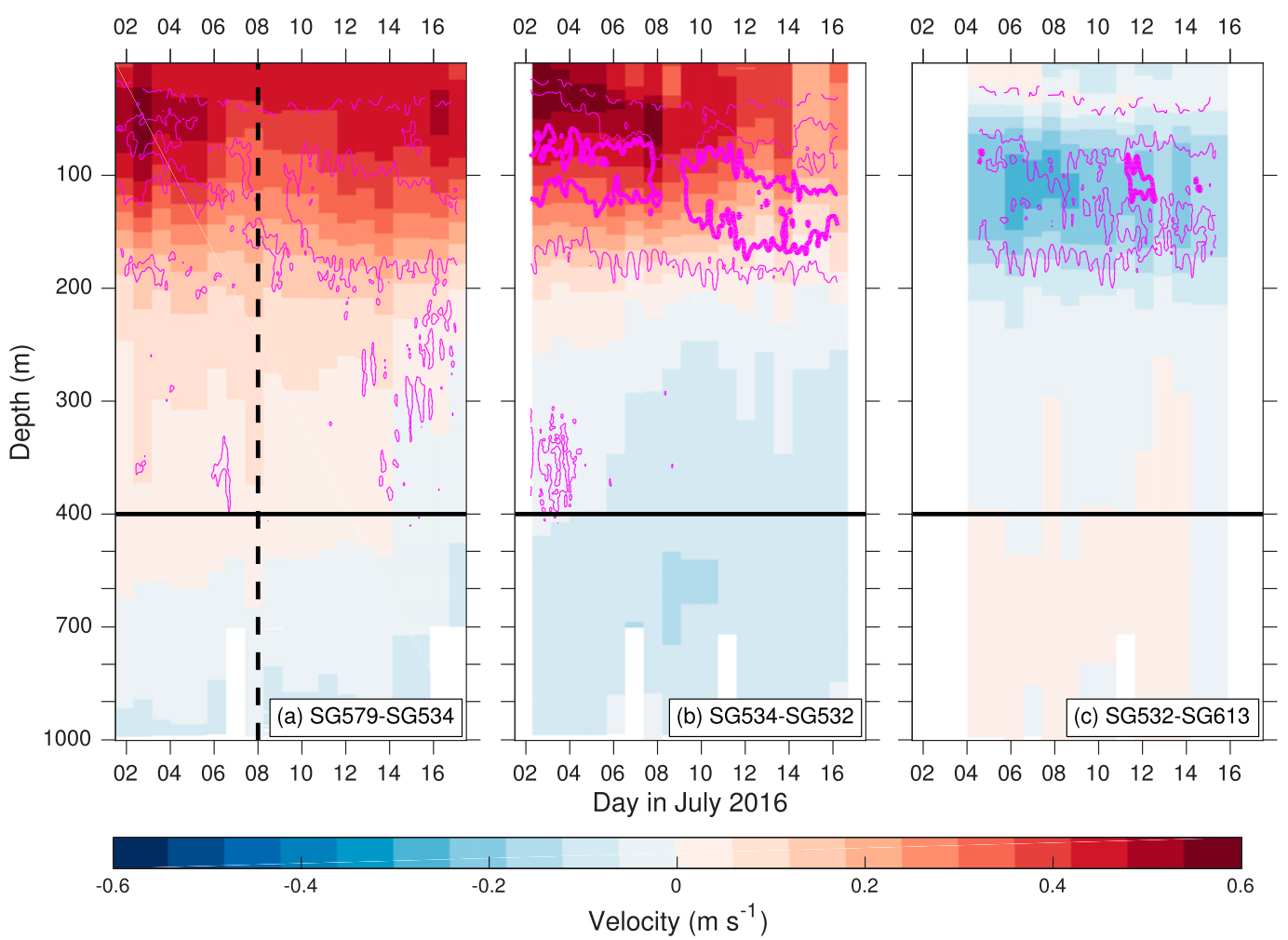

FIG. 7. Northward geostrophic velocity (shaded; $\mathrm{m} \mathrm{s}^{-1}$ ) and glider-pair mean salinity against time and depth, contoured at 34.5 (dashed), 35 (thin solid), and 35.25 (thick solid) $\mathrm{g} \mathrm{kg}^{-1}$ for glider pairings (a) SG579-SG534,

(b) SG534-SG532, and (c) SG532-SG620. Note the change in vertical scale at $400 \mathrm{~m}$. The vertical dashed line in

(a) indicates the time when $S G 579$ reached $85.3^{\circ} \mathrm{E}$.

radiation of Rossby waves across the BoB is shown in Fig. 10a (black line), superimposed on the SSH for 20 May 2016. The downwelling Kelvin wave visible at the equator at this time is forced by the seasonal westerly wind burst that typically occurs in early May (Fig. 11d) but was approximately one week later in 2016. Upon reaching the coast of Sumatra, such equatorial Kelvin waves turn into coastal Kelvin waves propagating northwestward and southeastward. The signal continues around the coastline of the BoB, radiating Rossby waves that propagate westward across the $\mathrm{BoB}$ (Shankar et al. 2002; Wijesekera et al. 2016). Intraseasonal variability associated with the Madden-Julian oscillation excites a similar dynamic response (Webber et al. 2010, 2012) and will also project onto variability of the SMC.

In the climatology (Fig. 10b), westerly winds amplify the Kelvin wave as it propagates along the equator at around $2.8 \mathrm{~m} \mathrm{~s}^{-1}$ (Fig. 11b), approximately the theoretical first baroclinic mode wave speed for this region (Chelton et al. 1998). The signal takes around 7 days to propagate from the equator along the coast of Sumatra and around the Andaman Sea. Although the propagation of the coastal signal into and around the Andaman Sea is complex and modified by local wind stress
(Chatterjee et al. 2017), a clear link is apparent between the equatorial Kelvin wave signal and the generation of the freely propagating Rossby wave signal at $8^{\circ} \mathrm{N}$ on 25 May (Figs. 10b,c). The subsequent seasonal Rossby wave signal propagates westward at around $0.3 \mathrm{~m} \mathrm{~s}^{-1}$, approximately the theoretical propagation speed of the first baroclinic mode Rossby wave at $8^{\circ} \mathrm{N}$ in the BoB (Killworth and Blundell 2005). The absolute $\mathrm{SSH}$ is reduced as this signal crosses the BoB owing to the climatological SSH gradient and the cyclonic wind stress curl in the western bay. Nevertheless, the SSH gradient in the region of the SMC is amplified as the Rossby wave reaches the middle of the $\mathrm{BoB}$ in late June.

In 2016, the signal from the Kelvin and Rossby waves is strengthened (Fig. 10c) as a result of a strong westerly wind burst in 2016 (Fig. 11b) and their propagation delayed relative to climatology (Fig. 10b). In addition, there appears to be a series of equatorial Kelvin waves forced at the equator between mid-May and late June, all of which generate Rossby waves, most likely originating from intraseasonal wind variability at the equator (Fig. 11). The first Rossby wave signal arrives in midJuly, after the SLD has weakened. 

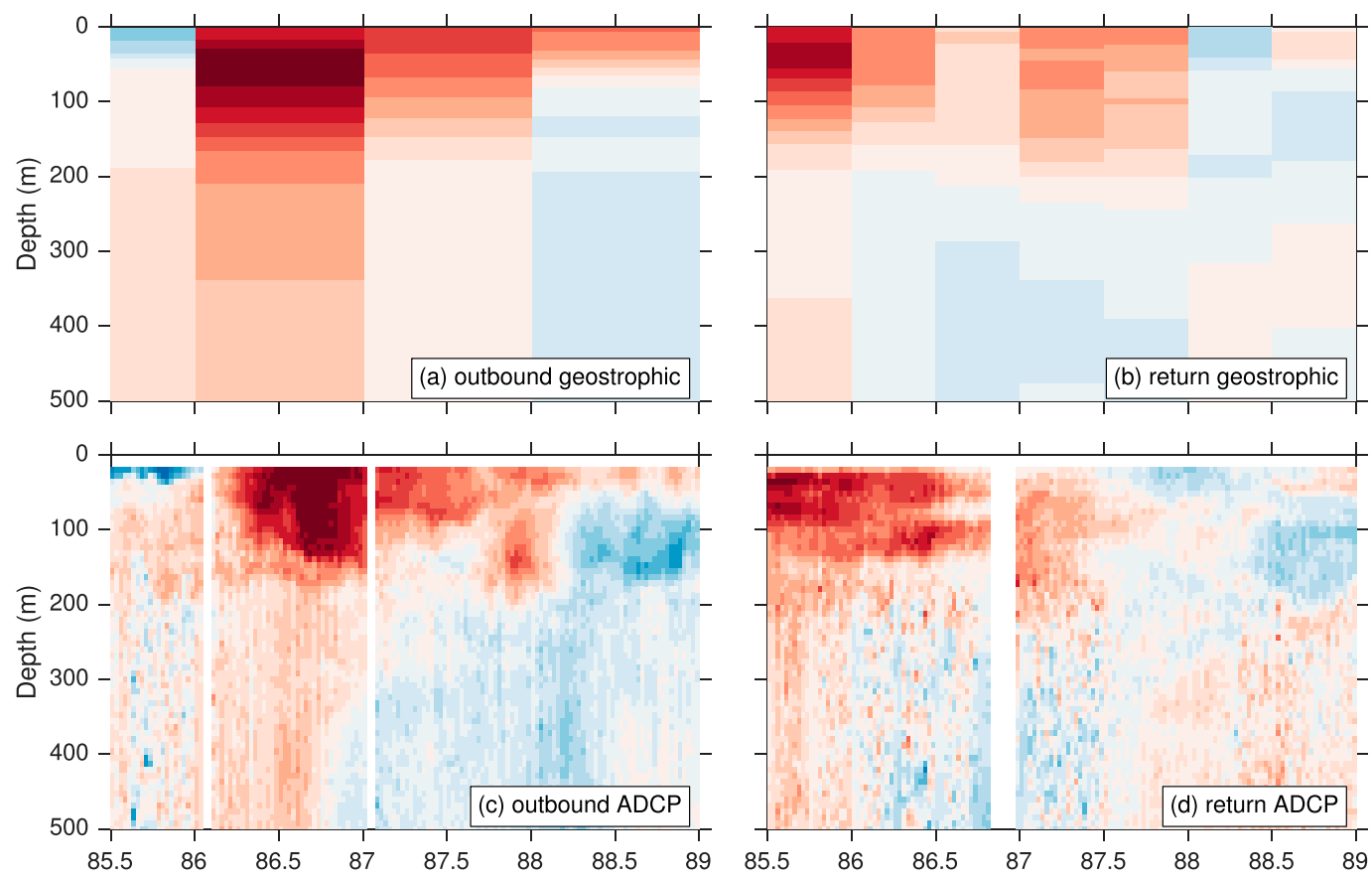

Longitude $\left({ }^{\circ} \mathrm{E}\right)$

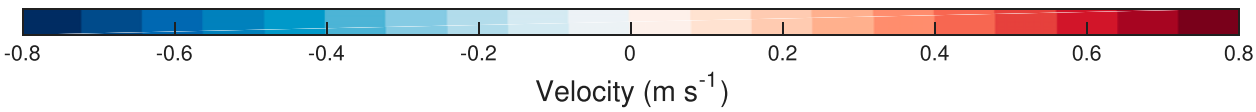

FIG. 8. Northward velocity (shaded; $\mathrm{m} \mathrm{s}^{-1}$ ) from ship measurements. (a),(b) Northward geostrophic velocity referenced to the shipboard ADCP for the outbound (30 Jun-4 Jul) and return (15-20 Jul) legs, respectively. (c),(d) Northward velocity from the shipboard ADCP for the outbound and return legs, respectively.

The equatorial Kelvin wave signal (represented by SSH at $0^{\circ}, 90^{\circ}-95^{\circ} \mathrm{E}$; orange line in Fig. $11 \mathrm{~b}$ ) is well correlated $(r=0.65)$ with the equatorial zonal wind stress $\tau_{x}$ at $80^{\circ}-90^{\circ} \mathrm{E}$ (purple line in Fig. 11b). In 2016 the SSH reached a peak far larger than at any other point in the preceding five years, thus generating the strong wave signal apparent in Fig. 10c. The wind stress was stronger than usual for this time of year, but other peaks of similar magnitude are evident in the 5-yr time series; therefore it is likely that the large-scale SSH anomalies associated with the negative Indian Ocean dipole (Saji et al. 1999) in June 2016 (Fig. 11a) also contribute to the magnitude of the SSH peak.

The northward velocity associated with the SMC (black line in Fig. 11d) is strongly correlated $(r=0.88)$ with the SSH difference (magenta line in Fig. 11d) between $8^{\circ} \mathrm{N}, 90^{\circ}-95^{\circ} \mathrm{E}$ (high $\mathrm{SSH}$ due to propagating Rossby waves; red line in Fig. 11c) and $8^{\circ} \mathrm{N}, 83^{\circ}-85^{\circ} \mathrm{E}$ (low SSH associated with the SLD; blue line in Fig. 11c). Although the $\mathrm{SSH}$ at $90^{\circ}-95^{\circ} \mathrm{E}$ reaches its highest value for five years in July 2016, the SSH gradient and SMC velocity are strong but not exceptional, owing to the relatively high SSH in the SLD.
The strength of the SLD (blue line in Fig. 11e) is influenced by local wind stress curl (green line in Fig. 11e). Cyclonic curl generates Ekman divergence, upwelling, and a local SSH minimum in the SLD (Vinayachandran and Yamagata 1998). The strong SLD in June 2016 can be directly related to a peak in wind stress curl that occurred shortly before. After this, the wind stress curl reduced dramatically, allowing the SLD to decay slightly during early July. However, the correlation of the SLD and the wind stress curl is relatively weak $(r=-0.32)$, indicating that processes other than local wind stress curl also modify the SLD. It may be that wind stress curl at other latitudes influences the SLD at $8^{\circ} \mathrm{N}$. In addition, downwelling seasonal Rossby waves will reduce the strength of the SLD independent of the local wind stress curl (Figs. 10b,c).

\section{Location of the SMC}

The longitudinal propagation of the SMC, associated with the propagation of the seasonal Rossby wave across the BoB, can be seen in maps of monthly mean surface velocity and SSH (Fig. 12), which show large changes in 


\section{Mean glider location}

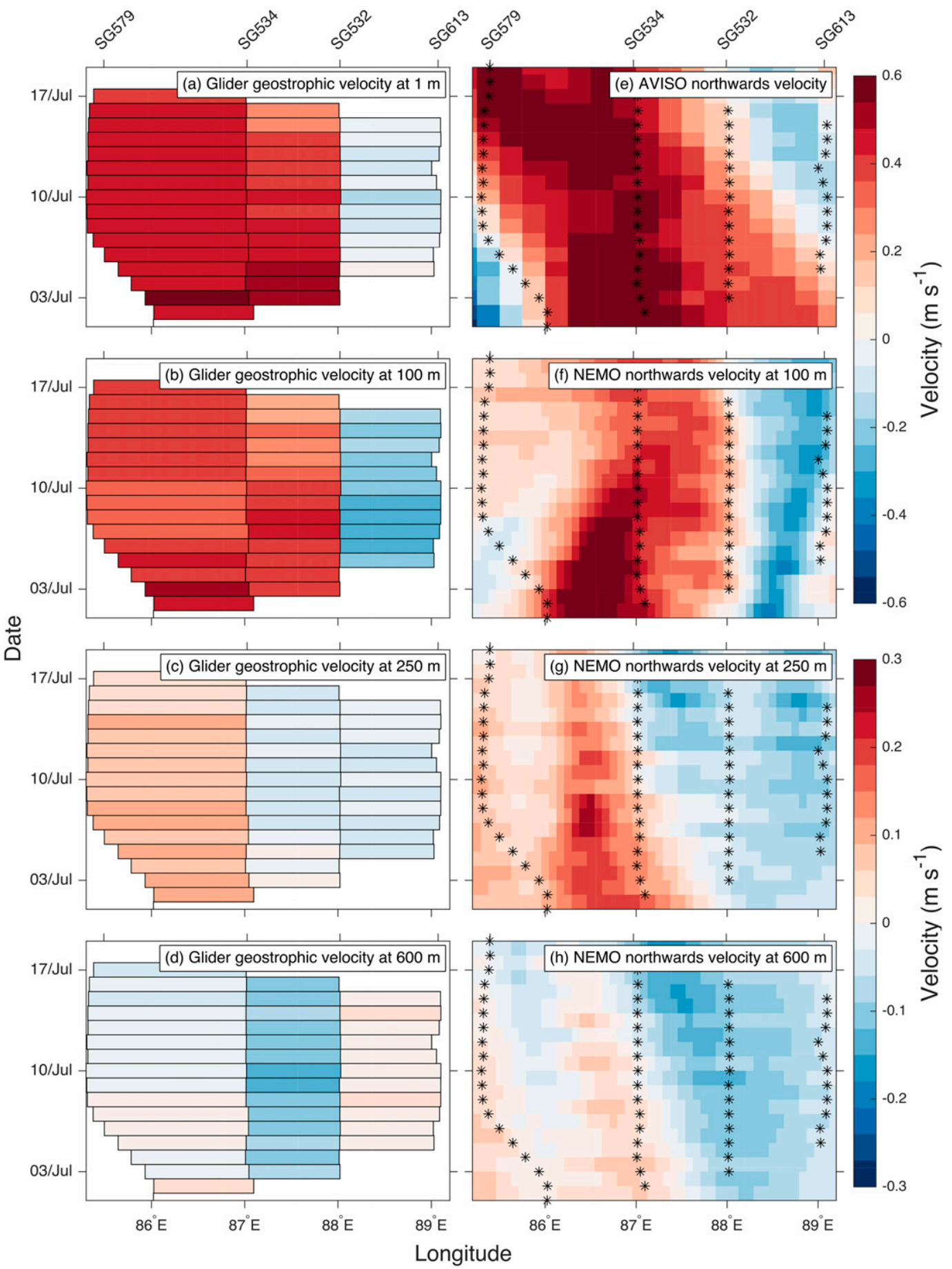

FIG. 9. (left) Northward glider-derived geostrophic velocity (shaded; $\mathrm{m} \mathrm{s}^{-1}$ ) against date and longitude at depths of (a) 1, (b) 100, (c) 250, and (d) $600 \mathrm{~m}$. (e) Surface northward geostrophic velocity (shaded; $\mathrm{m} \mathrm{s}^{-1}$ ) from AVISO and (f)-(h) northward velocity from NEMO ocean model (shaded; $\mathrm{m} \mathrm{s}^{-1}$ ) at depths of $100 \mathrm{~m}$ in (f), $250 \mathrm{~m} \mathrm{in} \mathrm{(g),} \mathrm{and}$ $600 \mathrm{~m}$ in $(\mathrm{h})$. In (e)-(h) the glider locations are shown as black asterisks. Note the change in color scale between the top four and bottom four panels. 

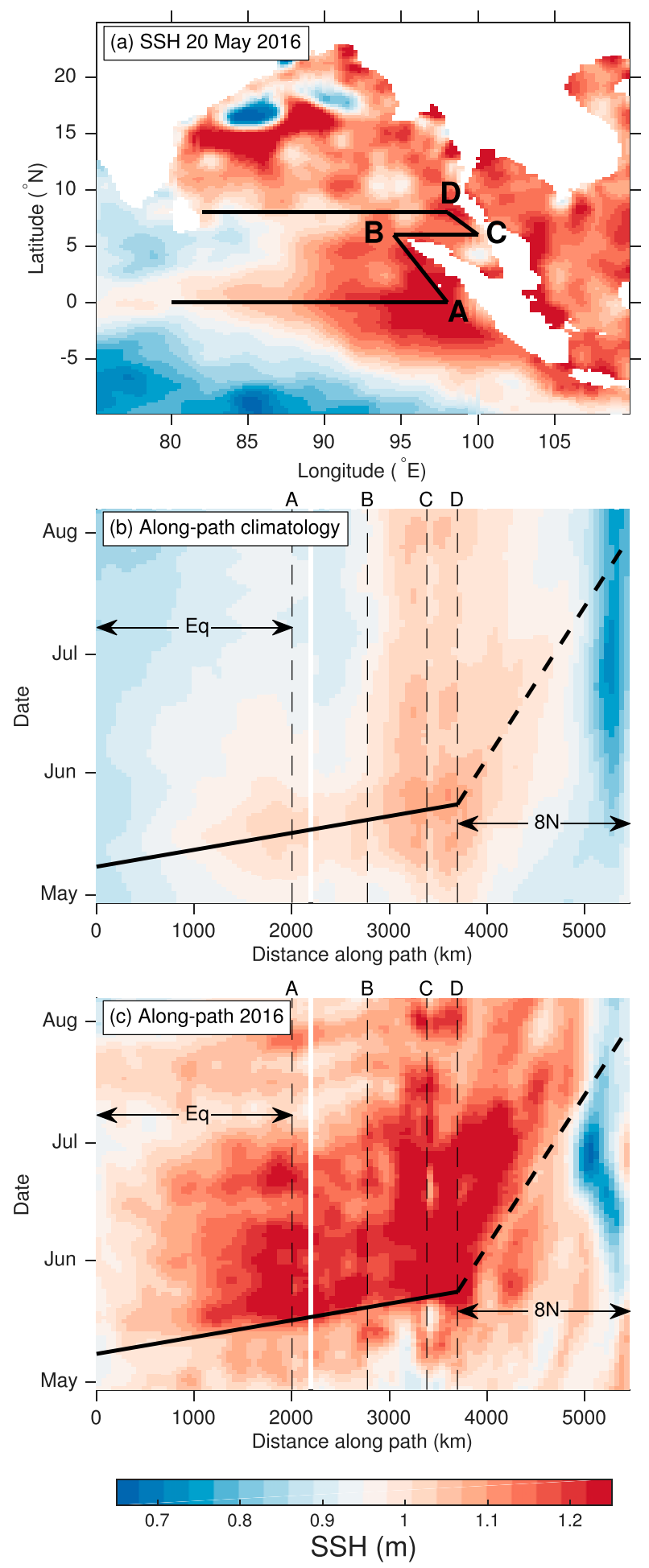

FIG. 10. (a) SSH (m; see color bar) from AVISO on 20 May 2016. (b) Hovmöller (time-distance) diagram of the 1993-2016 climatology of SSH along the example path shown as a solid black line in (a). The theoretical propagation of a first baroclinic mode Kelvin wave arriving at $8^{\circ} \mathrm{N}, 98^{\circ} \mathrm{E}$ on 30 May is shown by the thick solid black line, and the subsequent propagation of a theoretical first baroclinic mode Rossby wave along $8^{\circ} \mathrm{N}$ is shown by the thick dotted line. The locations of inflection points A-D in (a) are indicated as vertical dashed black lines. (c) As in (b), but for 2016. the flow field. In May, the main northward flow into the $\mathrm{BoB}$ is located around $92^{\circ} \mathrm{E}$. In June, much of the northward flow of the SMC is associated with the SLD, while part of the flow splits eastward. The northward flow east of $90^{\circ} \mathrm{E}$ in May and June is associated with the development of the seasonal Rossby wave at that time. The equatorial ocean Rossby wave signal propagating along $4^{\circ} \mathrm{N}$ deflects the eastward flow along the equator (evident in May) farther north. Between July and August, the westward propagation and weakening of the SMC seen at $8^{\circ} \mathrm{N}$ appears to be linked to weakening of the flow farther north in the BoB.

The evolution of the SSH and northward velocity along $8^{\circ} \mathrm{N}$ reveals the impact of propagating Rossby waves in 2016 and in the 1993-2016 climatology (Fig. 13; diagonal lines indicate the theoretical Rossby wave speed of $0.3 \mathrm{~m} \mathrm{~s}^{-1}$ ). In each year there is a combination of seasonal and intraseasonal variability in both SSH and velocity (evident for 2016 in Fig. 13), but in the climatology only the seasonal variability is evident as the timing of the intraseasonal waves varies from year to year. There is a clear displacement of the SLD (minimum in SSH) to the east in July with respect to climatology, as well as a late arrival of the Rossby wave signal (diagonal band of high SSH propagating from the east; Fig. 13a). Multiple Rossby waves cross the BoB each season, and the SLD goes through phases of strengthening and weakening, both in the climatology and in 2016 (Figs. 13a,b), which are mirrored by the northward velocity peaks in the SMC (Figs. 13c,d). The zonal velocity (not shown) shows a similar pattern to the meridional velocity, consistent with the steady direction of the SMC (Fig. 12) and also shows similar fluctuations associated with seasonal and intraseasonal Rossby waves propagating from the eastern boundary. In 2016, the SMC was strongest in late June, decaying gradually and moving westward during July and early August as the Rossby wave arrived but the SLD weakened. In late August-early September, local wind stress curl amplified the SLD and the strength of the SMC.

The subsurface impact of these dynamics at $110-\mathrm{m}$ depth in the NEMO model data at $8^{\circ} \mathrm{N}$ is shown in Fig. 14. Note that as the NEMO model assimilates SSH, this is not an independent verification, and we expect the near-surface variability in NEMO to be similar to that derived from SSH. The density from the NEMO ocean model (Figs. 14a,b) mirrors the SSH signal (Figs. 13a,b), with high density associated with the upwelling in the SLD and low density associated with the downwelling propagating Rossby waves. This signal is also apparent in the conservative temperature at $100-\mathrm{m}$ depth (Figs. 14e,f), which shows a gradient of more than $10^{\circ} \mathrm{C}$ across the $\mathrm{BoB}$ at $8^{\circ} \mathrm{N}$ in 2016. The northward 

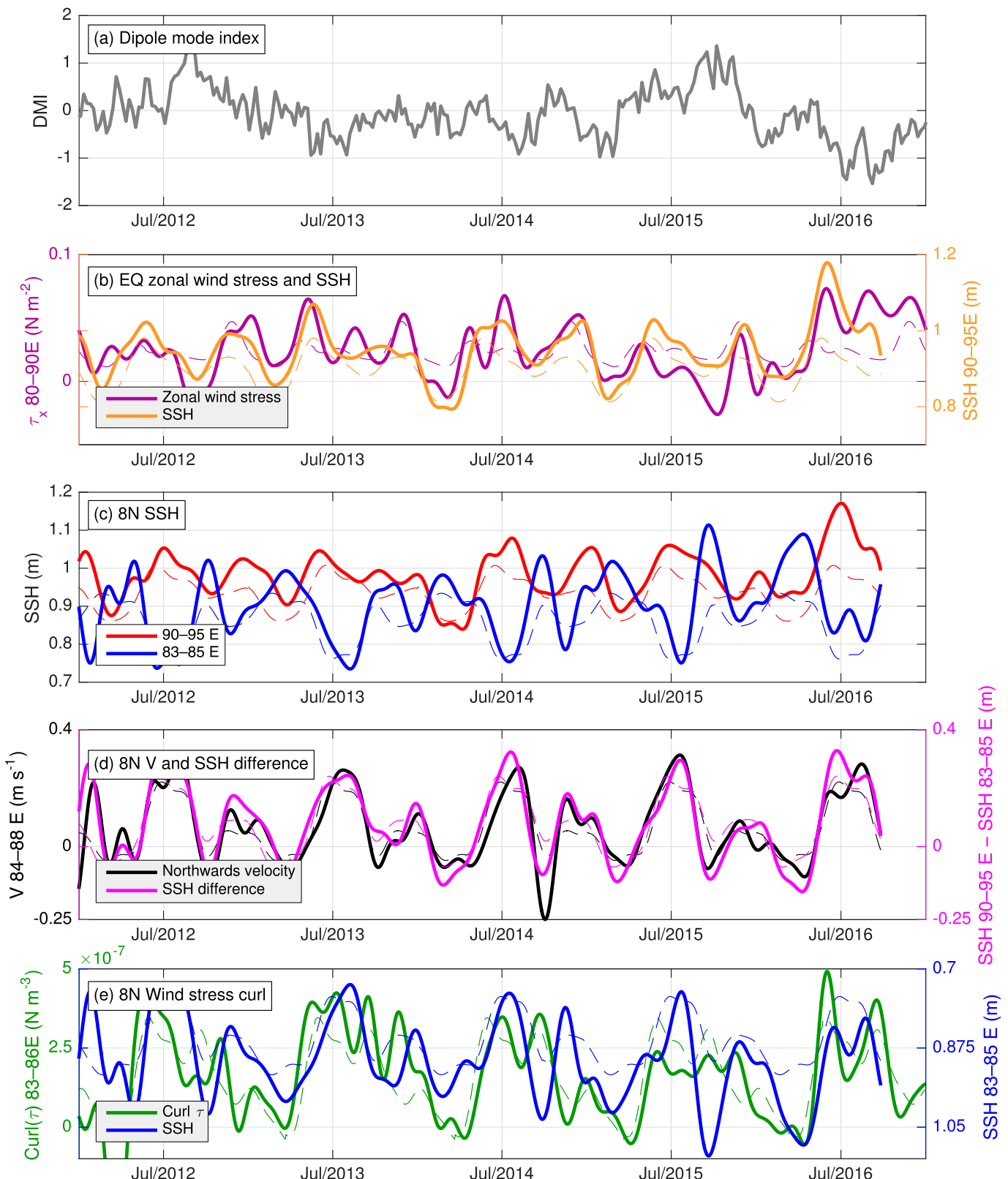

FIG. 11. (a) The weekly Indian Ocean dipole. The 60-day low-pass-filtered time series (thick solid) and repeating climatologies (thin dashed) of (b) ASCAT zonal wind stress at $0^{\circ}, 80^{\circ}-90^{\circ} \mathrm{E}\left(\mathrm{N} \mathrm{m}^{-2}\right.$; purple), SSH at $0^{\circ}, 90^{\circ}-95^{\circ} \mathrm{E}$ (m; orange). (c) $\mathrm{SSH}(\mathrm{m})$ from AVISO at $8^{\circ} \mathrm{N}, 90^{\circ}-95^{\circ} \mathrm{E}$ (red) and $8^{\circ} \mathrm{N} 83^{\circ}-85^{\circ} \mathrm{E}$ (blue). (d) Northward surface geostrophic velocity $\left(\mathrm{m} \mathrm{s}^{-1}\right.$ ) at $8^{\circ} \mathrm{N}, 84^{\circ}-88^{\circ} \mathrm{E}$ from AVISO (black); difference between SSH at $8^{\circ} \mathrm{N}, 90^{\circ}-95^{\circ} \mathrm{E}$ and $\mathrm{SSH}$ at $8^{\circ} \mathrm{N}, 83^{\circ}-85^{\circ} \mathrm{E}\left(\mathrm{m}\right.$; magenta). (e) ASCAT wind stress curl at $8^{\circ} \mathrm{N}, 83^{\circ}-85^{\circ} \mathrm{E}\left(\mathrm{N} \mathrm{m}^{-3}\right.$; green $)$ and SSH at $8^{\circ} \mathrm{N}$, $83^{\circ}-85^{\circ} \mathrm{E}(\mathrm{m}$; blue; note inverted vertical axis).

velocity at 100-m depth (Figs. 13b,c) associated with the SMC moves eastward through June and into July, before moving westward again, following the movement of the SLD. This northward flow is accompanied by a southward return flow just to the east associated with the anticyclonic eddy feature found here (Fig. 4) and consistent with the southward flow seen between SG532 and
SG613 in the glider data (Fig. 7c). The absolute salinity signal (Figs. 13g,h) closely follows the SMC movement in 2016 and in the climatology and aligns somewhat to the east of the northward core of the SMC, highlighting the role of this jet in advecting high-salinity water into the $\mathrm{BoB}$. The covariance of the location of the SMC, the core of ASHSW, and the southward return 

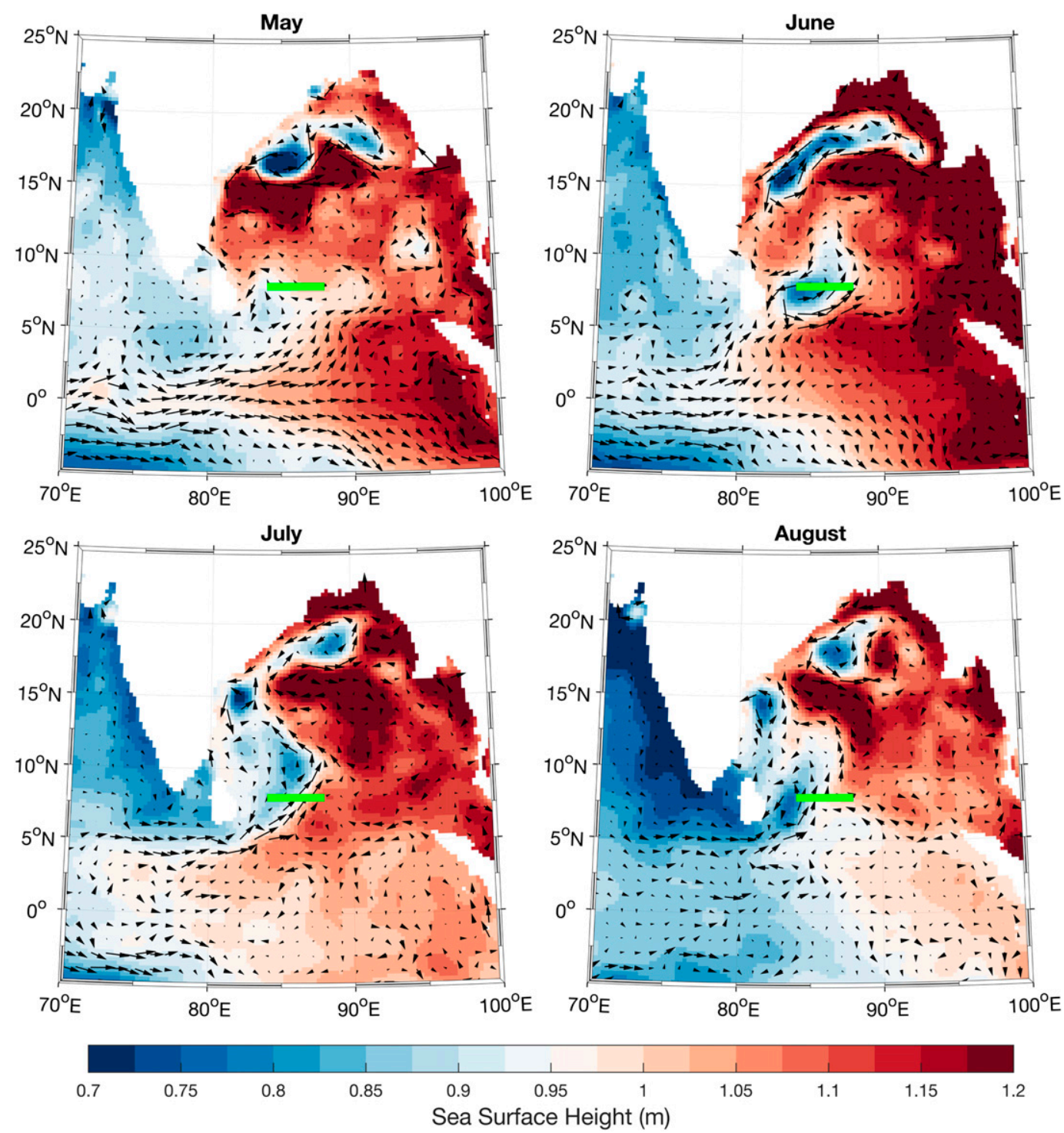

FIG. 12. Monthly mean velocity (vectors; $\mathrm{m} \mathrm{s}^{-1}$ ) and sea surface height (shaded; $\mathrm{m}$ ) from AVISO for (a) May 2016, (b) June 2016, (c) July 2016, (d) August 2016. The location of the BoBBLE section is shown by the thick green line.

flow support our hypothesis that these features are dynamically linked together and linked to the anticyclonic eddy farther east. It is also clear that the ASHSW is warmer than the water farther west, and further investigation shows that both temperature and salinity are elevated along the path of the SMC (not shown). We investigate the potential impact of these subsurface properties on the mixed layer temperature evolution in the next section.

\section{Impact of subsurface salinity advected by the SMC on SST}

We have shown above that the SMC advects warm and saline ASHSW into the subsurface BoB, which is known to influence the salinity budget of the BoB (Vinayachandran et al. 2013). It is likely that the advection of this water mass also has a direct impact on SST by altering the vertical structure of temperature and density, but this influence has not been previously quantified. To evaluate the impact of subsurface temperature and salinity differences between the ASHSW advected by the SMC and the colder, fresher water farther west (Fig. 14), we conduct a set of idealized KPP experiments with identical surface forcing but varying initial conditions below the surface mixed layer. These experiments quantify the impact of the advected ASHSW in an idealized framework without the influence of other processes such as horizontal advection or 

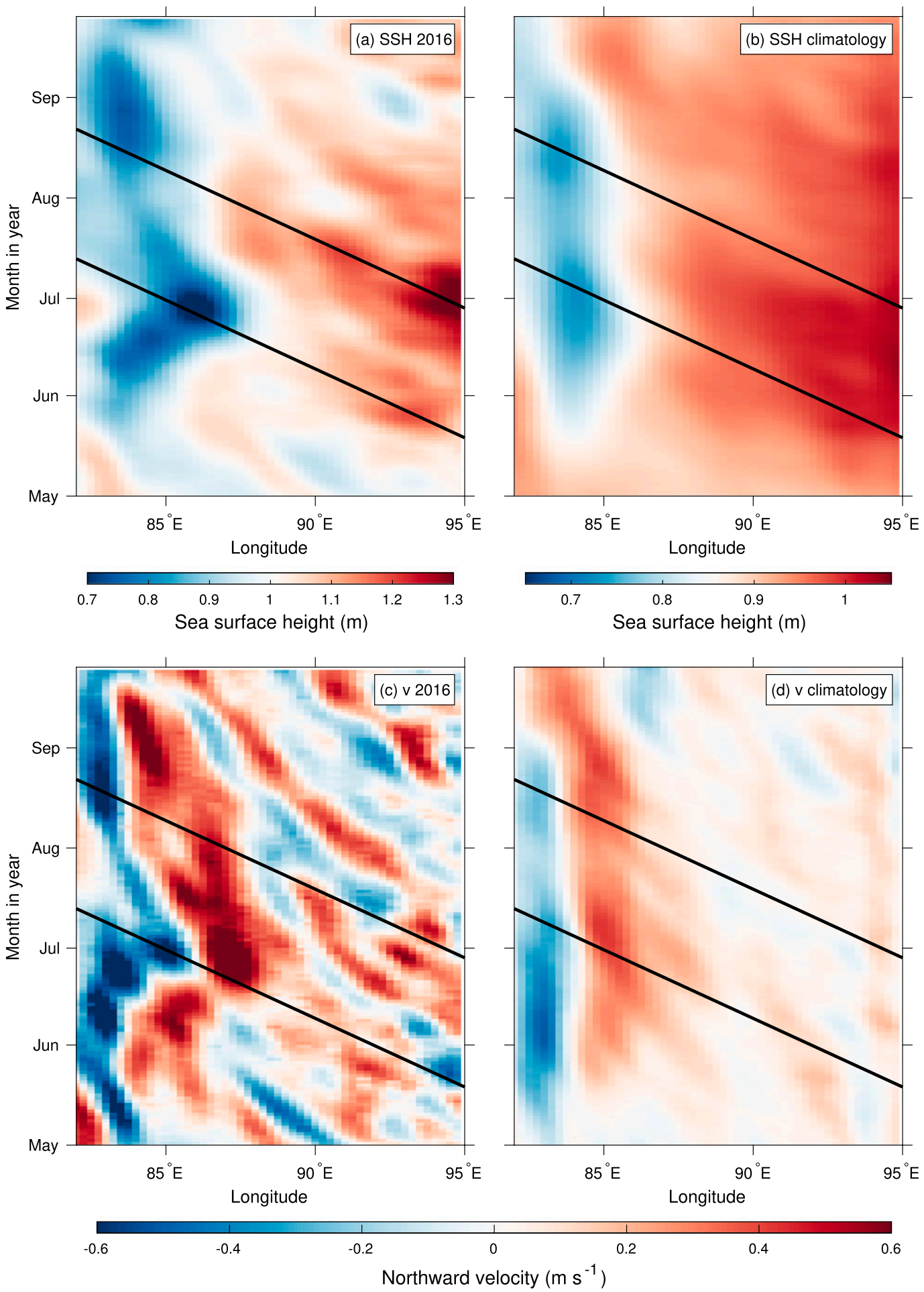

FIG. 13. Hovmöller (time-longitude) diagrams of (top) AVISO SSH (m) at $8^{\circ} \mathrm{N}$ (a) between May and September 2016 and (b) for the May-September climatology. (bottom) AVISO northward surface geostrophic velocity $\left(\mathrm{m} \mathrm{s}^{-1}\right)$ at $8^{\circ} \mathrm{N}$ (c) between May and September 2016 and (d) for the May-September climatology. Thick diagonal lines illustrate an idealized westward propagation speed of $0.3 \mathrm{~m} \mathrm{~s}^{-1}$. 

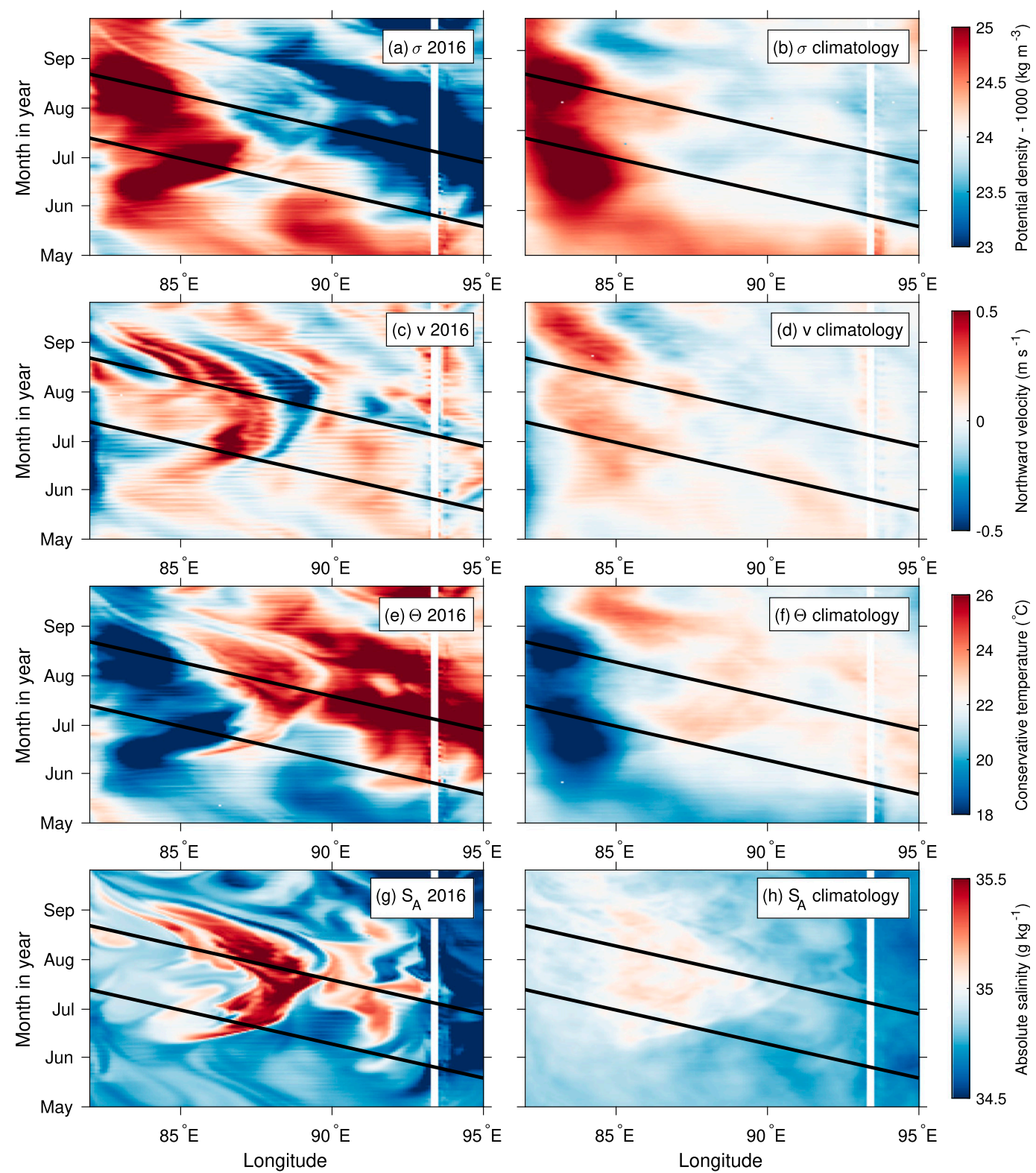

FIG. 14. Hovmöller (time-longitude) diagrams at 110-m depth from the NEMO ocean model at $8^{\circ} \mathrm{N}$ (left) between May and September 2016 and (right) for the May-September climatology. (a),(b) Density - $1000\left(\mathrm{~kg} \mathrm{~m}^{-3}\right)$. (c),(d) Northward velocity $\left(\mathrm{m} \mathrm{s}^{-1}\right)$. (e), (f) Conservative Temperature $\left({ }^{\circ} \mathrm{C}\right)$. (g), (h) Absolute Salinity $\left(\mathrm{g} \mathrm{kg}^{-1}\right)$. Thick diagonal lines illustrate an idealized westward propagation speed of $0.3 \mathrm{~m} \mathrm{~s}^{-1}$.

feedbacks on the surface fluxes that would complicate the picture in a more complex model.

The control initial conditions represent the mean vertical profiles of temperature and salinity from SG579 for $8-15$ July when SG579 was at $85.3^{\circ} \mathrm{E}$ and the highsalinity core was absent. The perturbation initial conditions are taken from the same time period from SG532 at $88^{\circ} \mathrm{E}$, in the heart of the high-salinity core at 50-200-m depth (Fig. 2). The properties within the mixed layer (the top $20 \mathrm{~m}$ ) are uniform with depth, and control and perturbation profiles are identical to 25 -m depth (Fig. 15e). Between 25 and $35 \mathrm{~m}$, the perturbation profiles are a linear blend between the profiles at SG579 and SG532, and below $35 \mathrm{~m}$ they represent the conditions at SG532. The increased temperature causes the perturbation density to be lower than the control below $40 \mathrm{~m}$, despite the generally higher salinity in the perturbation initial conditions (Fig. 15e).

The surface forcing (Figs. 15a,b) for both KPP simulations is identical and represents June-July 2016, to 

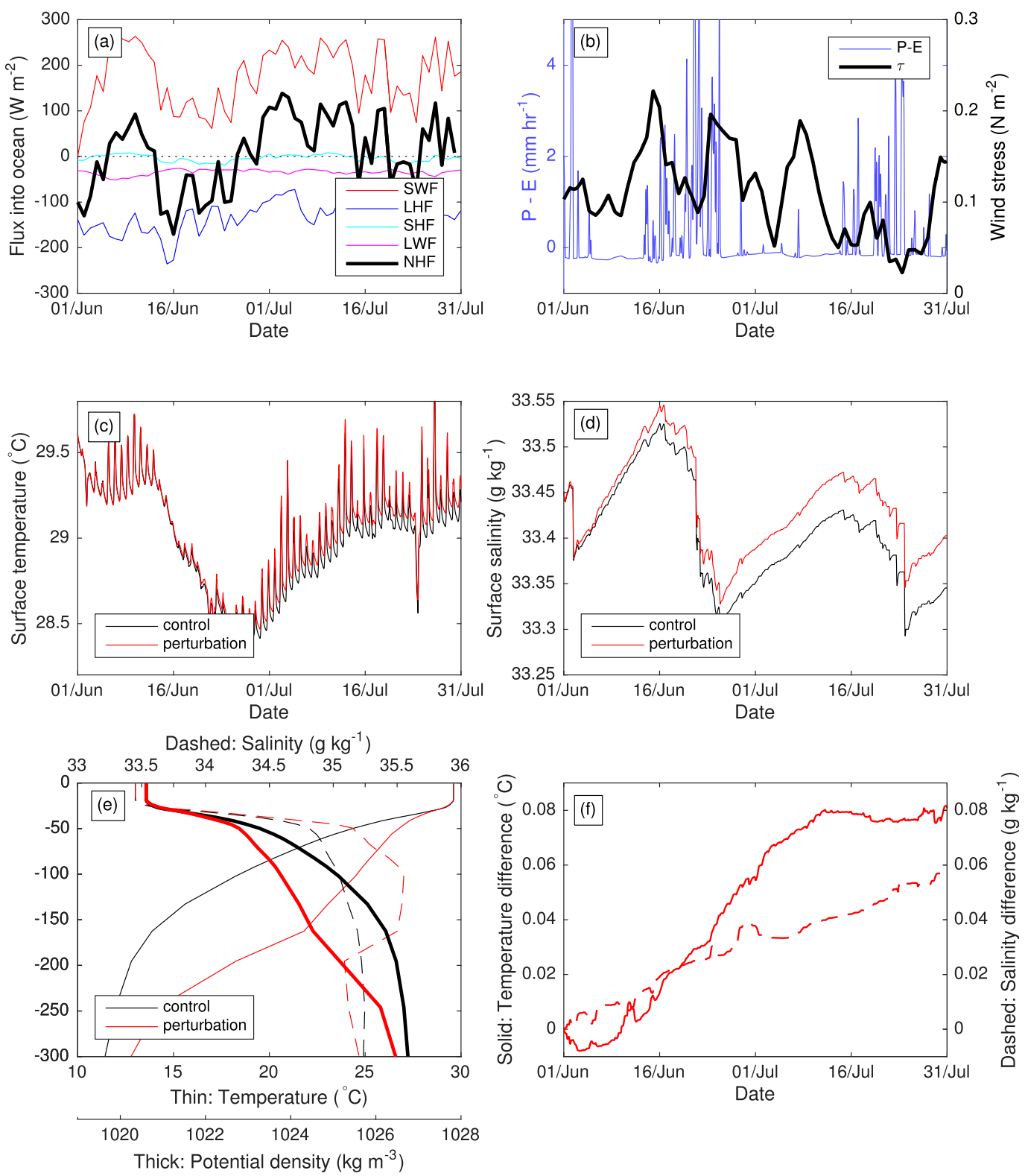

FIG. 15. Mixed layer model experiments. (a) Surface heat flux forcing ( $\mathrm{W} \mathrm{m}^{-2}$; positive into ocean): net solar flux (SWF; red), latent heat flux (LHF; blue), sensible heat flux (SHF; green), net longwave flux (LWF; magenta), and net heat flux (NHF; thick black line). (b) Precipitation minus evaporation $\left(P-E ; \mathrm{mm} \mathrm{h}^{-1}\right.$; blue) and total surface wind stress $\tau\left(\mathrm{N} \mathrm{m}^{-2}\right.$; thick black line). (c) Evolution of KPP surface temperature $\left({ }^{\circ} \mathrm{C}\right)$ for the control (black) and perturbation (red) simulations. (d) Evolution of KPP surface salinity $\left(\mathrm{g} \mathrm{kg}^{-1}\right)$ for the control (black) and perturbation (red) simulations. (e) Initial profiles of temperature $\left({ }^{\circ} \mathrm{C}\right.$; thin solid lines), salinity $\left(\mathrm{g} \mathrm{kg}^{-1}\right.$; thin dashed lines), and potential density $\left(\mathrm{kg} \mathrm{m}^{-3}\right.$; thick solid lines) for the control (black) and perturbation (red) simulations. (f) Difference in temperature $\left({ }^{\circ} \mathrm{C}\right.$; solid line) and salinity $\left(\mathrm{g} \mathrm{kg}^{-1}\right.$; dashed line) between the perturbation and control runs.

cover a full cycle of the BSISO, with initial negative net heat flux, high winds, and precipitation followed by a spell of positive net heat flux and lower precipitation (Lee et al. 2013). The solar shortwave flux is derived from 2-min observations of downwelling shortwave radiation from the Research Moored Array for
African-Asian-Australian Monsoon Analysis and Prediction (RAMA) mooring at $8^{\circ} \mathrm{N}, 90^{\circ} \mathrm{E}$, which we convert to net shortwave flux using albedo estimated from the solar elevation based on the Payne (1972) algorithm. The remaining surface fluxes and the surface wind stress are extracted at daily resolution from the TropFlux 
product (Kumar et al. 2012), which has been shown to better represent net heat flux and surface wind velocity in the $\mathrm{BoB}$, compared with other commonly used reanalysis products (Sanchez-Franks et al. 2018). Threehourly precipitation data from the Tropical Rainfall Measuring Mission (TRMM) are extracted for the same location, and evaporation is calculated from the TropFlux latent heat flux. The shortwave radiation is accumulated to hourly values, and all other variables are linearly interpolated to the same hourly resolution.

In both the control and perturbation experiments the surface temperature (Fig. 15c) follows the net heat flux as expected. Cooling is generally present throughout June, associated with the largely negative net heat flux at this time in the convectively active phase of the BSISO (Fig. 15a). The diurnal cycle is suppressed during this cooling phase until July when it becomes stronger owing to increased shortwave and net heat fluxes in the convectively active phase of the BSISO. As a result, the surface warms to almost its initial temperature by the end of the simulation. Meanwhile, the salinity (Fig. 15d) increases slightly during the simulation but is punctuated by sharp drops due to intermittent high precipitation. The overall increase in salinity is due to a combination of evaporation and vertical mixing from persistently strong winds (Fig. 15b). The amplitude of the variability over the active-break cycle associated with the BSISO is consistent with previous observational estimates (Vecchi and Harrison 2002).

The difference between control and perturbation experiments is shown in Fig. 15f. By the end of the simulation, the perturbation surface temperature is around $0.08^{\circ} \mathrm{C}$ warmer than the control, and the salinity is $0.06 \mathrm{~g} \mathrm{~kg}^{-1}$ higher. The magnitude of the temperature difference between the control and perturbation experiments is around $10 \%$ of the modeled variability over the lifetime of the BSISO cycle; therefore, this represents a significant modulation of SST that will also affect lateral SST gradients and thus atmospheric moisture convergence and convection. Most of the temperature difference accumulates between 10 June and 10 July 2016, associated with strong winds, mixed layer deepening, and entrainment. Since the perturbation initial conditions have warmer and saltier water below the mixed layer, this accounts for the reduced cooling and increased salinity. The salinity changes during the simulation are around $20 \%$ of the variability over the entire run, representing an important difference to the evolution of mixed layer salinity and stratification. As this water is advected into and around the $\mathrm{BoB}$, this difference in mixed layer salinity may further influence the stratification and air-sea interaction on longer time scales than accounted for here. In summary, we find that the advection of subsurface
ASHSW by the SMC has the potential to alter SST and thus the development of monsoon rainfall systems over the BoB.

\section{Discussion}

During the summer of 2016, the SMC was farther east than usual and close to the annual maximum strength. The surface winds over the BoB were weaker than climatology in July, and while the wind stress curl that drives upwelling in the SLD was strong in June it weakened considerably in July. A strong westerly wind burst in May led to a strong dynamical signal propagating along the eastern boundary of the $\mathrm{BoB}$ and radiating westward as Rossby waves. However, this signal did not arrive until late July when the SLD was substantially weaker than climatology. Therefore, the combination of factors did not produce an unusually strong SMC despite the strong equatorial signal, highlighting the complexity of the dynamical interactions that determine the strength of this current (Fig. 16).

The glider observations of the northward velocity and transport have been shown to be consistent with both satellite-altimetry-derived estimates of the northward surface velocity and with a high-resolution numerical ocean model with data assimilation (the $1 / 12^{\circ}$ global NEMO model). Examination of the flow fields and temporal variability reveal that the northward flow of the SMC is enhanced by recirculations in the SLD and the anticyclonic eddy to the east of the SMC but that these features are slowly varying and the northward flow was fairly stable, weakening gradually during the deployment. The northward flow was strongest in the surface $200 \mathrm{~m}$, with the maximum depth of northward flow observed at $550 \mathrm{~m}$ at the western end of the section. The anticyclonic eddy to the east of the SMC was associated with southward flow with a subsurface maximum around $100 \mathrm{~m}$, which was also persistent in the NEMO model data. The mean northward transport was $21 \mathrm{~Sv}$, with a range of $17-25 \mathrm{~Sv}$ and an uncertainty of $\pm 4 \mathrm{~Sv}$ during the deployment. This is larger than the maximum SMC transport estimated by Wijesekera et al. (2016) from mooring measurements (8-16 Sv in summer 2014, depending on the uncertain width of the SMC) and larger than the seasonal mean transport estimate of $10 \mathrm{~Sv}$ of Vinayachandran et al. (1999). Since our observations were during a period of anomalously strong deep northward flow, the discrepancy with the seasonal mean estimate is unsurprising. The disagreement with the estimate of Wijesekera et al. (2016) is likely down to uncertainty in the width of the SMC, since they scaled velocity estimates by an estimated current width of $100-200 \mathrm{~km}$. This is smaller than the $300-\mathrm{km}$-wide 


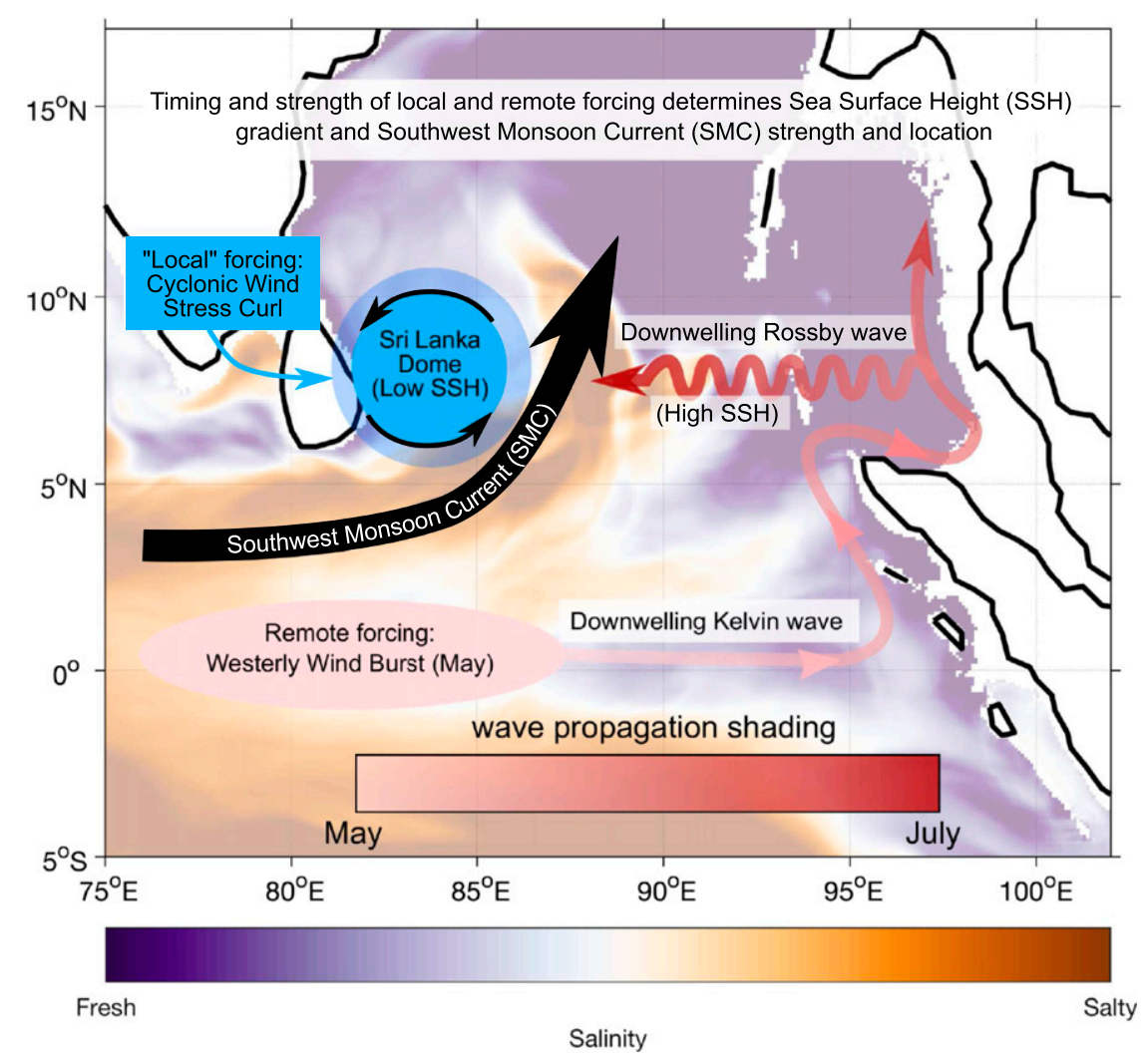

FIG. 16. Schematic of the mechanisms governing the strength and location of the SMC.

northward near-surface flow observed in 2016 but may be more representative of the width of the continuous flow from the Arabian Sea into the BoB and associated water mass transport.

The subsurface salinity maximum was observed to the east of the SMC core, being nonexistent in the observed data at $85.3^{\circ}-86^{\circ} \mathrm{E}$ (SG579). This feature was strongest at $88^{\circ} \mathrm{E}$ and variable at $87^{\circ}$ and $89^{\circ} \mathrm{E}$. The NEMO model suggests this feature is persistent and follows the lateral movements of the SMC, a hypothesis that seems to be supported by the temporary disappearance of this feature in the glider data at $87^{\circ} \mathrm{E}$ coinciding with the maximum eastward displacement of the SMC. Whether the strength of this feature varies with the strength of the SMC is not clear; the maximum salinity and lateral extent appears fairly constant during the observations and throughout the 2016 season in the NEMO model, and it is likely that the exact pathway of the SMC strongly influences the strength of this feature. As the ASHSW is also relatively warm, the density of this water mass is less than the density of the fresher but cooler water farther west (Fig. 9), generating a density gradient that strengthens the subsurface SMC to the west of the ASHSW core and generates the anticylonic eddy with southward flow to the east. Therefore, there is a feedback from the advected ASHSW onto the strength and location of the SMC. Over time, this will tend to favor westward propagation of the SMC and the advected ASHSW, as observed (Fig. 14).

We use idealized one-dimensional modeling experiments to test the hypothesis that the advection of the subsurface warm and salty ASHSW will exert a significant influence on the evolution of SST. Idealized KPP experiments confirm that initial conditions with subsurface ASHSW led to an increase in SST of $0.08^{\circ} \mathrm{C}$ relative to initial conditions from the SLD. Although some of this difference is due to the relatively cold subsurface waters in the SLD, the ASHSW is typically warmer than the surrounding water masses. Over the course of the two-month simulation, the mixed layer salinity increased by $0.06 \mathrm{~g} \mathrm{~kg}^{-1}$, which would continue to influence the stratification of the BoB and thus air-sea interaction over longer time scales. Thus, the strength and location of the SMC, and the associated strength and location of the SLD, will modify the spatial gradient in SST and the development of monsoon depressions, leading to changes in the location and quantity of monsoon rainfall around the BoB. Furthermore, our simulations do not account for the pumping of the subsurface water into the mixed layer (Vinayachandran et al. 2013), which would 
act to amplify the temperature and salinity difference between regions with and without the subthermocline ASHSW water mass. Since these events are localized and episodic, it is not trivial to assess their impact using a one-dimensional (1D) model.

The strength of the SMC will vary in response to atmospheric forcing on a range of time scales, from intraseasonal to interannual. At intraseasonal time scales, the MJO is known to force oceanic equatorial Kelvin waves that will eventually generate Rossby waves propagating across the $\mathrm{BoB}$ and influencing the strength of the SMC, while the BSISO will modulate the strength of the winds at the equator and in the BoB, leading to changes in both the Rossby wave signal and local upwelling. Given that the strength and position of the SMC will influence the distribution of SST across the southern $\mathrm{BoB}$, such intraseasonal variability in the strength of the SMC is likely to influence the intraseasonal atmospheric variability in turn. This represents a complex and hitherto unknown feedback mechanism between intraseasonal variability in the ocean and atmosphere. In addition, over longer time scales the supply of salt and heat to the subthermocline BoB is crucial for determining the stratification the $\mathrm{BoB}$ and thus the strength of air-sea interaction (Shenoi et al. 2002), suggesting that the seasonal strength of the SMC may alter the strength of air-sea interaction and thus the amplitude of subseasonal variability in following years.

This study demonstrates that the SMC is dynamically complex and significantly impacts the ocean properties at $8^{\circ} \mathrm{N}$. The transport of water masses and their eventual distribution by this current will be investigated in a separate paper. Given the existing difficulties shown here in modeling these features (e.g., the subsurface salinity maximum, which was entirely absent from the MOM model), this work highlights the importance of improving our understanding of the key processes determining the subsurface ocean conditions across the BoB and their subsequent impacts on the surface temperature and thus monsoon rainfall.

Acknowledgments. The authors thank two anonymous reviewers for comments that helped to greatly improve the manuscript. BoBBLE is a joint MoES, India-NERC, United Kingdom, program. The BoBBLE field program onboard R/V Sindhu Sadhana was funded by Ministry of Earth Sciences, Govt. of India, under its Monsoon Mission program administered by the Indian Institute of Tropical Meteorology, Pune. The support and cooperation of the captain, officers, and crew of R/V Sindhu Sadhana are greatly appreciated. BGMW and ALSF were supported by the NERC BoBBLE project (NE/L013827/1 and NE/L013835/1, respectively). DBB has been supported by Office of Naval Research Global NICOP program (Award N6290915-1-2021-P00001 to the University of Warsaw). The altimeter products were produced by SSALTO/Duacs and distributed by AVISO, with support from CNES (http:// www.aviso.altimetry.fr/duacs/). ASCAT winds were obtained from Ifremer (www.ifremer.fr). The weekly dipole mode index data were obtained from NOAA (http:// stateoftheocean.osmc.noaa.gov/sur/ind/dmi.php). The NEMO model was produced by Mercator Ocean (www. mercator-ocean.fr) and accessed through the Copernicus Marine Environment Monitoring Service (marine. copernicus.eu). Glider data were processed using the UEA glider toolbox (http://www.byqueste.com/toolbox. html), and the authors thank Bastien Queste for help using this software. The optimal interpolation was carried out on the High Performance Computing Cluster supported by the Research and Specialist Computing Support service at the University of East Anglia. The data used in this study are available from the corresponding author on reasonable request.

\section{REFERENCES}

Behara, A., and P. N. Vinayachandran, 2016: An OGCM study of the impact of rain and river water forcing on the Bay of Bengal. J. Geophys. Res. Oceans, 121, 2425-2446, https:// doi.org/10.1002/2015JC011325.

Bretherton, F. P., R. E. Davis, and C. B. Fandry, 1976: A technique for objective analysis and design of oceanographic experiment applied to MODE-73. Deep-Sea Res., 23, 559-582, https:// doi.org/10.1016/0011-7471(76)90001-2.

Chatterjee, A., D. Shankar, J. P. McCreary, P. N. Vinayachandran, and A. Mukherjee, 2017: Dynamics of Andaman Sea circulation and its role in connecting the equatorial Indian Ocean to the Bay of Bengal. J. Geophys. Res. Oceans, 122, 3200-3218, https://doi.org/10.1002/2016JC012300.

Chelton, D. B., R. A. DeSzoeke, M. G. Schlax, K. El Naggar, and N. Siwertz, 1998: Geographical variability of the first baroclinic Rossby radius of deformation. J. Phys. Oceanogr., 28, 433-460, https://doi.org/10.1175/1520-0485(1998)028<0433: GVOTFB $>2.0 . \mathrm{CO} ; 2$.

Damerell, G. M., K. J. Heywood, and D. P. Stevens, 2013: Direct observations of the Antarctic circumpolar current transport on the northern flank of the Kerguelen Plateau. J. Geophys. Res. Oceans, 118, 1333-1348, https://doi.org/10.1002/ jgrc.20067.

Das, U., P. N. Vinayachandran, and A. Behara, 2016: Formation of the southern Bay of Bengal cold pool. Climate Dyn., 47, 20092023, https://doi.org/10.1007/s00382-015-2947-9.

Dee, D. P., and Coauthors, 2011: The ERA-Interim reanalysis: Configuration and performance of the data assimilation system. Quart. J. Roy. Meteor. Soc., 137, 553-597, https://doi.org/ 10.1002/qj.828.

Frajka-Williams, E., C. C. Eriksen, P. B. Rhines, and R. R. Harcourt, 2011: Determining vertical water velocities from Seaglider. J. Atmos. Oceanic Technol., 28, 1641-1656, https:// doi.org/10.1175/2011JTECHO830.1. 
Gadgil, S., 2003: The Indian monsoon and its variability. Annu. Rev. Earth Planet. Sci., 31, 429-467, https://doi.org/10.1146/ annurev.earth.31.100901.141251.

Girishkumar, M. S., M. Ravichandran, and M. J. McPhaden, 2013: Temperature inversions and their influence on the mixed layer heat budget during the winters of 2006-2007 and 2007-2008 in the Bay of Bengal. J. Geophys. Res. Oceans, 118, 2426-2437, https://doi.org/10.1002/jgrc.20192.

Jain, V., and Coauthors, 2017: Evidence for the existence of Persian Gulf water and Red Sea water in the Bay of Bengal. Climate Dyn., 48, 3207-3226, https://doi.org/10.1007/s00382-016-3259-4.

Jensen, T. G., 2001: Arabian Sea and Bay of Bengal exchange of salt and tracers in an ocean model. Geophys. Res. Lett., 28, 3967-3970, https://doi.org/10.1029/2001GL013422.

- H. W. Wijesekera, E. S. Nyadjro, P. G. Thoppil, J. F. Shriver, K. K. Sandeep, and V. Pant, 2016: Modeling salinity exchanges between the equatorial Indian Ocean and the Bay of Bengal. Oceanography, 29 (2), 92-101, https://doi.org/ 10.5670/oceanog.2016.42.

Killworth, P. D., and J. R. Blundell, 2005: The dispersion relation for planetary waves in the presence of mean flow and topography. Part II: Two-dimensional examples and global results. J. Phys. Oceanogr., 35, 2110-2133, https://doi.org/10.1175/ JPO2817.1.

Kumar, B. P., J. Vialard, M. Lengaigne, V. S. N. Murty, and M. J. McPhaden, 2012: TropFlux: Air-sea fluxes for the global tropical oceans-description and evaluation. Climate Dyn., 38, 1521-1543, https://doi.org/10.1007/s00382-011-1115-0.

Large, W. G., J. C. McWilliams, and S. C. Doney, 1994: Oceanic vertical mixing: A review and a model with a nonlocal boundary layer parameterization. Rev. Geophys., 32, 363-403, https://doi.org/10.1029/94RG01872.

Lee, C., and Coauthors, 2016: Collaborative observations of boundary currents, water mass variability, and monsoon response in the Southern Bay of Bengal. Oceanography, 29 (2), 102-111, https://doi.org/10.5670/oceanog.2016.43.

Lee, J.-Y., B. Wang, M. C. Wheeler, X. Fu, D. E. Waliser, and I.-S. Kang, 2013: Real-time multivariate indices for the boreal summer intraseasonal oscillation over the Asian summer monsoon region. Climate Dyn., 40, 493-509, https://doi.org/ 10.1007/s00382-012-1544-4.

Le Traon, Y. P., F. Nadal, and N. Ducet, 1998: An improved mapping method of multisatellite altimeter data. J. Atmos. Oceanic Technol., 15, 522-534, https://doi.org/10.1175/ 1520-0426(1998)015<0522:AIMMOM > 2.0.CO;2.

Madec, G., and Coauthors, 2008: NEMO ocean engine. IPSL Note du Pôle de Modélisation 27, 357 pp.

Matthews, A. J., D. B. Baranowski, K. J. Heywood, P. J. Flatau, and S. Schmidtko, 2014: The surface diurnal warm layer in the Indian Ocean during CINDY/DYNAMO. J. Climate, 27, 9101-9123, https://doi.org/10.1175/JCLI-D-14-00222.1.

McCreary, J. P., P. K. Kundu, and R. L. Molinari, 1993: A numerical investigation of dynamics, thermodynamics and mixed-layer processes in the Indian Ocean. Prog. Oceanogr. 31, 181-244, https://doi.org/10.1016/0079-6611(93)90002-U.

_- W. Han, D. Shankar, and S. R. Shetye, 1996: Dynamics of the East India Coastal Current: 2. Numerical solutions. J. Geophys. Res., 101, 13 993-14 010, https://doi.org/10.1029/96JC00560.

McDougall, T. J., and P. M. Barker, 2011: Getting started with TEOS-10 and the Gibbs Seawater (GSW) oceanographic toolbox. SCOR/IAPSO Working Group Rep., 28 pp.

— , and Coauthors, 2010: The international thermodynamic equation of seawater 2010: Calculation and use of thermodynamic properties. Intergovernmental Oceanographic Commission Manuals and Guides 56, 196 pp., http://www.teos-10.org/pubs/ TEOS-10_Manual.pdf.

Murty, V. S. N., Y. V. B. Sarma, D. P. Rao, and C. S. Murty, 1992: Water characteristics, mixing and circulation in the Bay of Bengal during southwest monsoon. J. Mar. Res., 50, 207-228, https://doi.org/10.1357/002224092784797700.

Payne, R. E., 1972: Albedo of the sea surface. J. Atmos. Sci., 29, 959-970, https://doi.org/10.1175/1520-0469(1972)029<0959: AOTSS $>2.0 . C O ; 2$.

Saji, N. H., B. N. Goswami, P. N. Vinayachandran, and T. Yamagata, 1999: A dipole mode in the tropical Indian Ocean. Nature, 401, 360-363, https://doi.org/10.1038/43854.

Sanchez-Franks, A., E. C. Kent, A. J. Matthews, B. G. M. Webber, S. C. Peatman, and P. N. Vinayachandran, 2018: Intraseasonal variability of air-sea fluxes over the Bay of Bengal during the southwest monsoon. J. Climate, 31, 7087-7109, https://doi.org/ 10.1175/JCLI-D-17-0652.1.

Schott, F., J. Reppin, J. Fischer, and D. Quadfasel, 1994: Currents and transports of the Monsoon Current south of Sri Lanka. J. Geophys. Res., 99, 25127-25141, https://doi.org/10.1029/ 94JC02216.

Shankar, D., P. Vinayachandran, and A. Unnikrishnan, 2002: The monsoon currents in the north Indian Ocean. Prog. Oceanogr., 52, 63-120, https://doi.org/10.1016/S0079-6611(02)00024-1.

Shenoi, S. S. C., D. Shankar, and S. R. Shetye, 2002: Differences in heat budgets of the near-surface Arabian Sea and Bay of Bengal: Implications for the summer monsoon. J. Geophys. Res., 107, 3052, https://doi.org/10.1029/2000JC000679.

Thompson, A. F., and K. J. Heywood, 2008: Frontal structure and transport in the northwestern Weddell Sea. Deep-Sea Res. I, 55, 1229-1251, https://doi.org/10.1016/j.dsr.2008.06.001.

Todd, R. E., D. L. Rudnick, M. R. Mazloff, R. E. Davis, and B. D. Cornuelle, 2011: Poleward flows in the southern California Current System: Glider observations and numerical simulation. J. Geophys. Res., 116, C02026, https://doi.org/10.1029/ $2010 \mathrm{JC} 006536$.

Vecchi, G. A., and D. E. Harrison, 2002: Monsoon breaks and subseasonal sea surface temperature variability in the Bay of Bengal. J. Climate, 15, 1485-1493, https://doi.org/10.1175/ 1520-0442(2002)015<1485:MBASSS > 2.0.CO;2.

Vinayachandran, P. N., and T. Yamagata, 1998: Monsoon response of the sea around Sri Lanka: Generation of thermal domes and anticyclonic vortices. J. Phys. Oceanogr., 28, 1946-1960, https://doi.org/10.1175/1520-0485(1998)028<1946: MROTSA $>2.0 . \mathrm{CO} ; 2$.

_ , Y. Masumoto, T. Mikawa, and T. Yamagata, 1999: Intrusion of the Southwest Monsoon Current into the Bay of Bengal. J. Geophys. Res., 104, 11 077-11 085, https://doi.org/10.1029/ 1999JC900035.

, D. Shankar, S. Vernekar, K. K. Sandeep, P. Amol, C. P. Neema, and A. Chatterjee, 2013: A summer monsoon pump to keep the Bay of Bengal salty. Geophys. Res. Lett., 40, 17771782, https://doi.org/10.1002/grl.50274.

_- and Coauthors, 2018: BoBBLE (Bay of Bengal Boundary Layer Experiment): Ocean-atmosphere interaction and its impact on the South Asian monsoon. Bull. Amer. Meteor. Soc., 99, 1569-1587, https://doi.org/10.1175/ BAMS-D-16-0230.1.

Wang, B., and X. Xie, 1997: A model for the boreal summer intraseasonal oscillation. J. Atmos. Sci., 54, 72-86, https:// doi.org/10.1175/1520-0469(1997)054<0072:AMFTBS>2.0. $\mathrm{CO} ; 2$. 
Webber, B. G. M., A. J. Matthews, and K. J. Heywood, 2010: A dynamical ocean feedback mechanism for the Madden-Julian oscillation. Quart. J. Roy. Meteor. Soc., 136, 740-754, https:// doi.org/10.1002/qj.604.

, D. P. Stevens, A. J. Matthews, and K. J. Heywood, 2012: Dynamical ocean forcing of the Madden-Julian oscillation at lead times of up to five months. J. Climate, 25, 2824-2842, https://doi.org/10.1175/JCLI-D-11-00268.1.

, A. J. Matthews, K. J. Heywood, J. Kaiser, and S. Schmidtko, 2014: Seaglider observations of equatorial Indian Ocean Rossby waves associated with the Madden-Julian oscillation.
J. Geophys. Res. Oceans, 119, 3714-3731, https://doi.org/ 10.1002/2013JC009657.

Wijesekera, H. W., W. J. Teague, D. W. Wang, E. Jarosz, T. G. Jensen, S. U. P. Jinadasa, H. J. S. Fernando, and Z. R. Hallock, 2016: Low-frequency currents from deep moorings in the southern Bay of Bengal. J. Phys. Oceanogr., 46, 3209-3238, https://doi.org/10.1175/JPO-D-16-0113.1.

You, Y., and M. Tomczak, 1993: Thermocline circulation and ventilation in the Indian Ocean derived from water mass analysis. Deep-Sea Res. I, 40, 13-56, https://doi.org/10.1016/ 0967-0637(93)90052-5. 